\title{
A HOMOGENEOUS CONSTITUTIVE MODEL FOR MASONRY
}

\author{
J. LOPEZ ${ }^{1}$, S. OLLER ${ }^{1, *}$, E. OÑATE ${ }^{1}$ AND J. LUBLINER ${ }^{2}$ \\ ${ }^{1}$ E.T.S. Ingenieros de Caminos, Canales y Puertos, Universidad Politécnica de Cataluña, Campus Norte UPC, \\ Gran Capitán s/n, 08034 Barcelona, Spain \\ ${ }^{2}$ Civil Engineering Department, University of California at Berkeley, Berkeley, U.S.A.
}

\begin{abstract}
SUMMARY
Masonry has been a broadly used material since the beginning of human life. Despite its popularity, the analysis of masonry structures is a complex task due to the heterogeneity and the non-linear material behaviour. The need for reliable analysis procedures capable of predicting damage evolution and failure in historical structures in order to design efficient repair and maintenance has motivated the work of many structural analysts in this field. Here the finite element method has emerged as one of the most powerful procedures for linear and non-linear analysis of masonry structures. The main problem pending is the development of accurate and efficient constitutive models capable of predicting the behaviour of masonry in the non-linear range and this has been the motivation of this work.

The constitutive model presented is based on the homogenized anisotropic elastoplasticity previously developed by the authors. The effect of anisotropy is introduced by means of fictitious isotropic stress and strain spaces. The material properties in the fictitious isotropic spaces are mapped into the actual anisotropic space by means of a consistent fourth-order tensor. The advantage of the model is that the classical theory of plasticity can be used to model the non-linear behaviour in the isotropic spaces.

Details of the model for masonry structures and its implementation in a general non-linear finite element code are given. Examples of application to the analysis of some masonry structures are presented, showing the efficiency of the model. Copyright (C) 1999 John Wiley \& Sons, Ltd.
\end{abstract}

KEY WORDS: composite material; numerical methods; constitutive models; homogenization techniques; masonry

\section{INTRODUCTION}

Masonry is regarded as a precursor of engineering structures, and its design and analysis are often based on simplified methods that do not adequately reflect all the complex structural mechanisms or are over-conservative. However, there are advanced analytical techniques based on the finite element method, such as those developed from the theories of micromodelling, macromodelling and the theory of composites [1-4].

The present work deals with a homogenized constitutive model for the analysis of masonry previously developed by the authors $[4,6,9,10-12]$ and followed within the Civil Engineering

\footnotetext{
* Correspondence to: S. Oller, E.T.S. Ingenieros de Caminos, Canales y Puertos, Universidad Politécnica de Cataluña, Campus Norte UPC, Gram Capitán s/n, 08034 Barcelona, Spain. E-mail: cimne@etseccpb.upc.es

CCC 0029-5981/99/341651-21\$17.50

Copyright (C) 1999 John Wiley \& Sons, Ltd.

Received 1 September 1998

Revised 1 February 1999
} 
Diploma Thesis of López [5]. This technique allows mesh generation in a simple manner without the high computational cost for discretizing the bricks and joints. The model uses homogeneous elements that intrinsically include the mechanical and geometrical properties of the different components. Given the anisotropic nature of the material, the Space Transformation Theory, described by Oller et al. [6], has been implemented with the objective of working with fictitious isotropic spaces and adapting usual techniques to elasto-plastic analysis.

\section{MASONRY}

Masonry can be regarded as a combination of two material phases constituted by blocks, natural or manufactured, such as bricks, and a series of mortar joints arranged irregularly (as in stone masonry) or regularly (as in brickwork). In the latter, the joints follow the boundaries of the bricks forming two main groups: horizontal and vertical. The present work will focus on masonry composed of regular geometrical bricks without considering irregular blocks.

As a material, masonry has different properties depending on the direction in which the mortar joints are oriented since they constitute its weak planes. Failure of these structures is generally
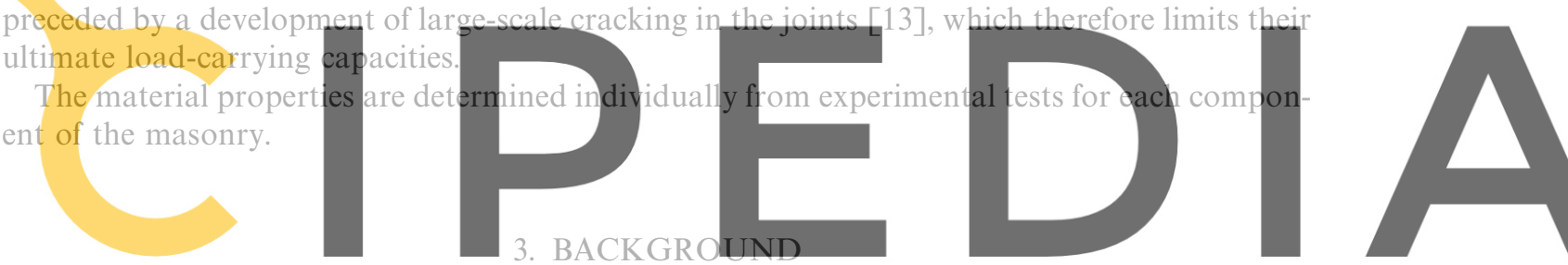

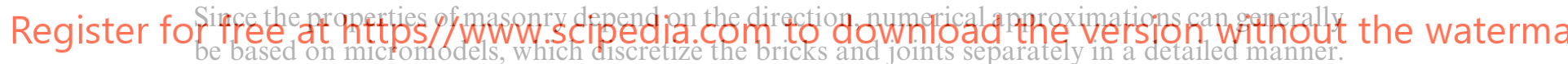

On the other hand, masonry can be treated as a composite macromodel. Depending on the

desired scale, it is possible to use the following forms of modelling.

Detailed micromodelling: bricks and mortar are represented by continuous elements, while the behaviour of the mortar-brick interface is represented by discontinuous elements.

Simplified micromodelling: the materials are represented by a continuous element where the behaviour of the mortar joints and the interfaces are separated by discontinuities.

Macromodelling: the bricks, mortar and interfaces are globally represented by the same element.

The model has been developed for brick walls subjected to in-plane loading [7], which is a most common case in masonry. In the past, most of the analyses considered masonry as an assembly of blocks and mortar with similar properties. Assuming isotropic and elastic behaviour for components as well as the entire masonry was performed the analysis in order to simplify the problem.

Another model worth mentioning is that developed by Pietruszcak [3] which considers that a masonry panel, in the macromodelling level, could be taken as a two-phase composite consisting of brick units crossed by two orthogonal groups of mortar joints.

Other important macromodel are that of Luccioni [2] based on the application of the composite theory, and those of Anthoine [1] and Lourenço [8]. 

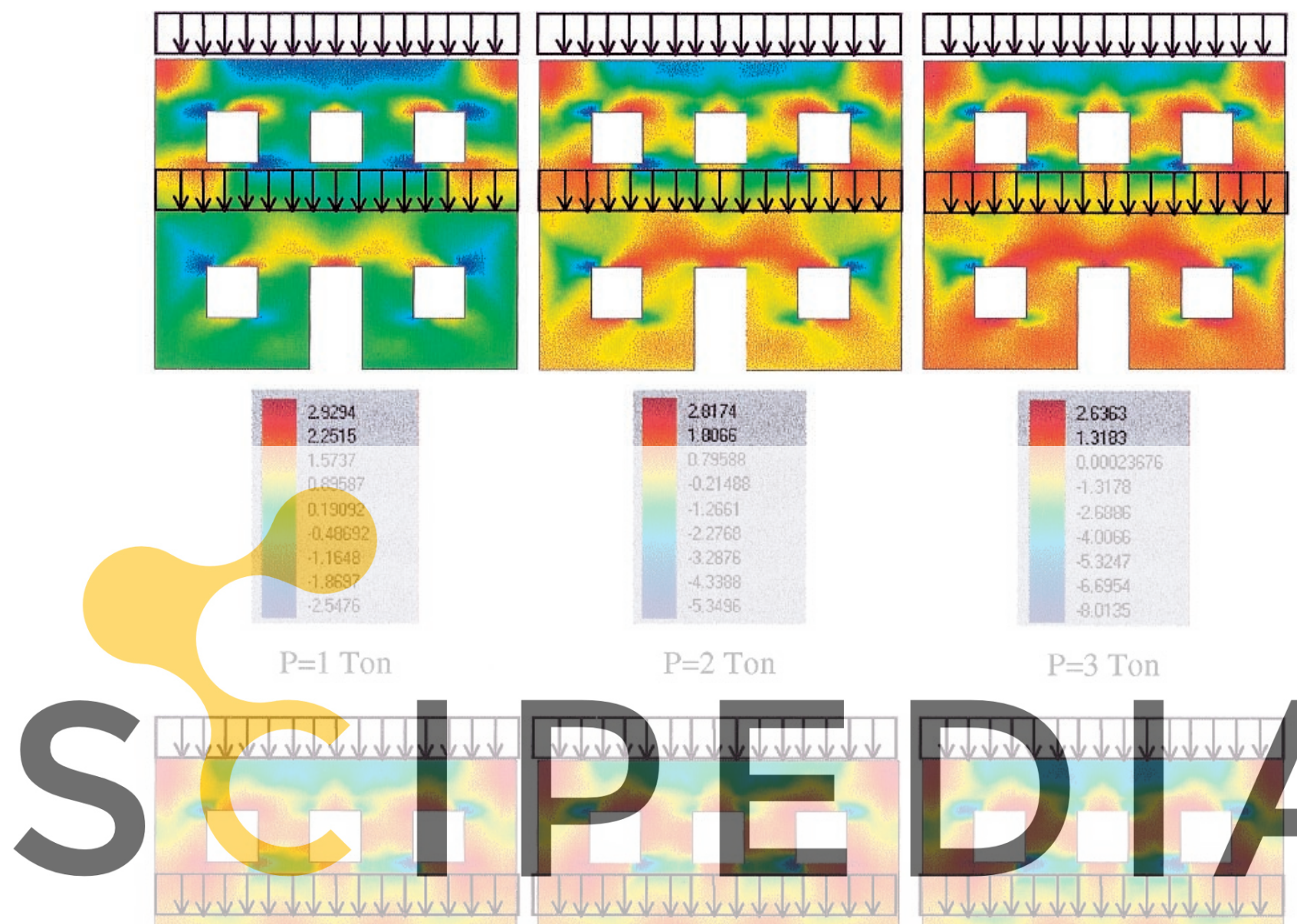

Register for free at https//www.scipedia.com to download the version without the watermark
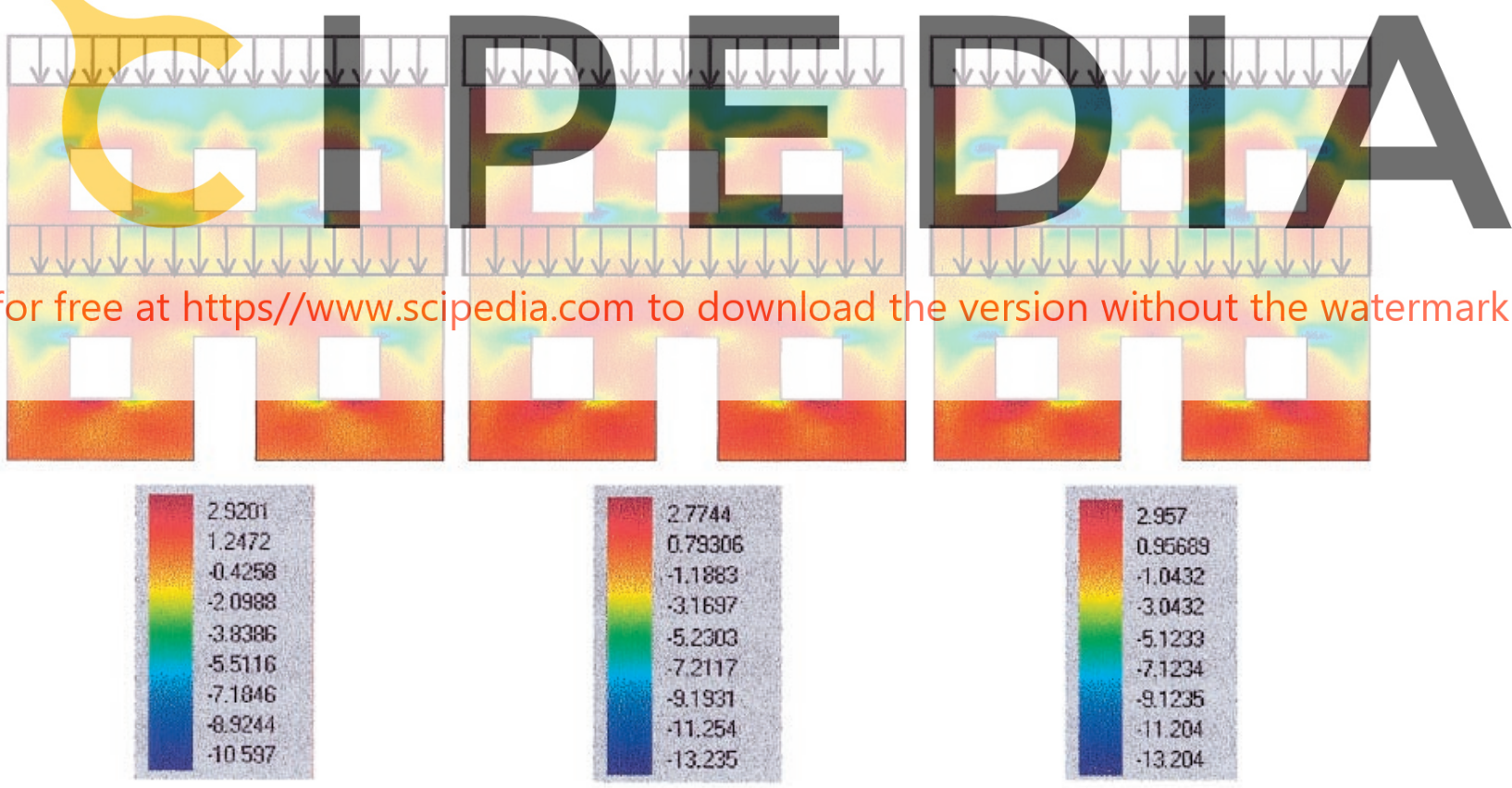

\section{$\mathrm{P}=3$ Ton}
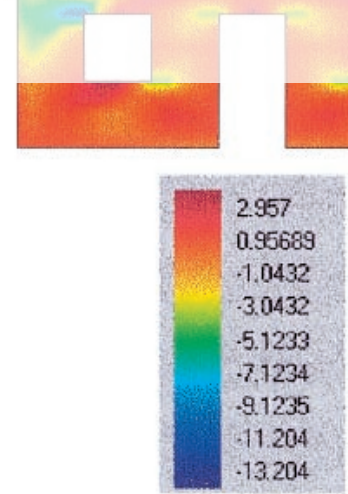

Plate 1. Panel with gravitational and vertical uniform loads. $\sigma_{1}-$ principal stress 


\section{THE PROPOSED MODEL}

The model that will be presented here is based on a study of the compatibility and equilibrium of a 'basic cell' of masonry under different conditions of loading (see Figure 1). The main assumptions are:

(1) The height and depth of the structural element are large compared to its thickness, which permits the assumption of plane stress since the loading is in-plane.

(2) Given the arrangement of the bricks and mortar joints the composite can be treated as orthotropic.

The constitutive model is based on the formulation, for each of the deformation modes of the basic cell (Figure 1), of the equilibrium and compatibility equations (Figure 2). These are introduced in the constitutive equations of each material component, obtaining expressions for the stress-strain behaviour of the composite, as well as the homogenized mechanical parameters.

\subsection{Mode 1 equations}
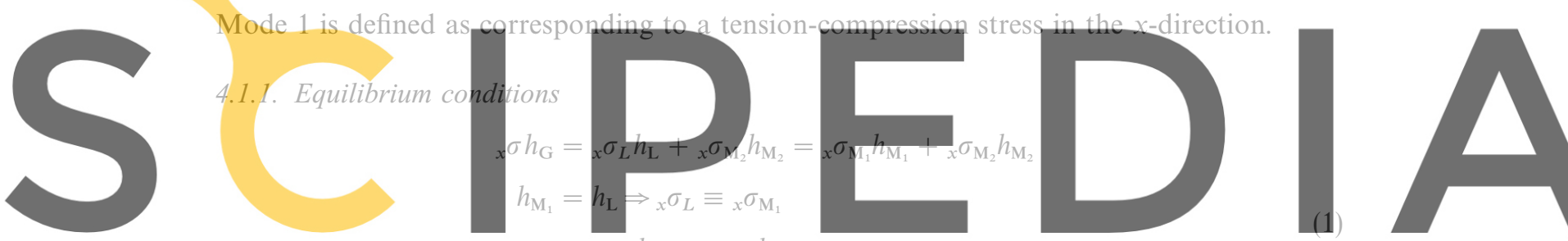

Register for free at https//www.scipedia.com to

$$
{ }_{x} \sigma={ }_{x} \sigma_{\mathrm{M}_{1}} \frac{h_{\mathrm{M}_{1}}}{h_{\mathrm{G}}}+{ }_{x} \sigma_{\mathrm{M}_{2}} \frac{h_{\mathrm{M}_{2}}}{h_{\mathrm{G}}}
$$

${ }_{i} \sigma_{j}$ represents the homogeneous stress state in the ' $i$ ' direction of material ' $j$ ', $h_{i}$ represents the height of the ' $i$ ' material component.

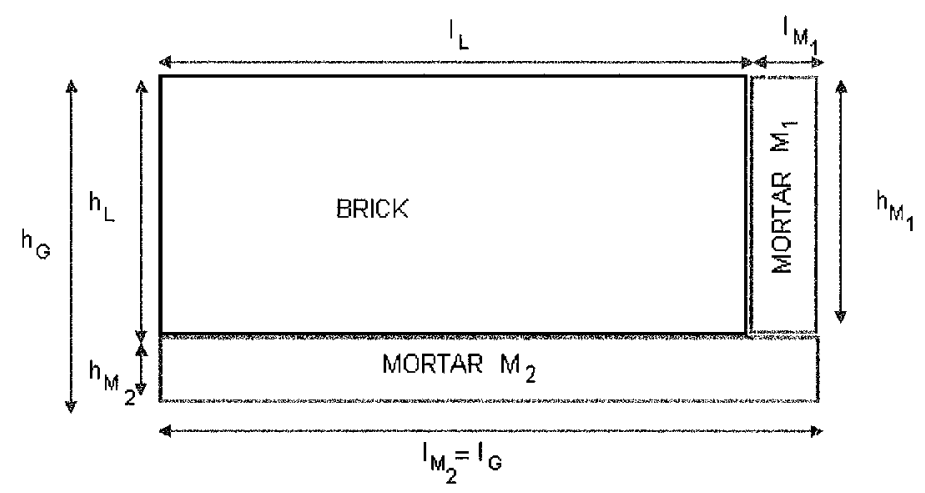

Figure 1. Notation used in the dimensions of the component elements in the basic cell 


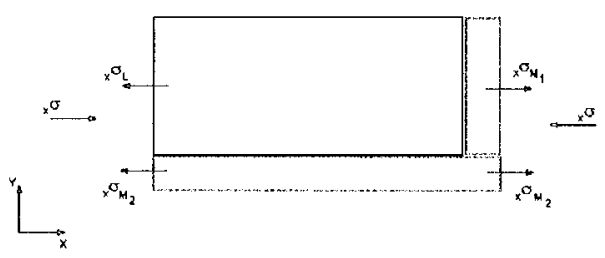

Representation of Mode I.

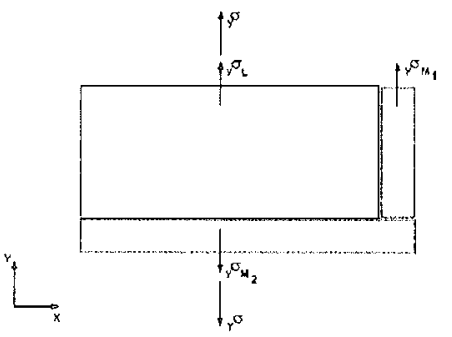

Representation of Mode 2.
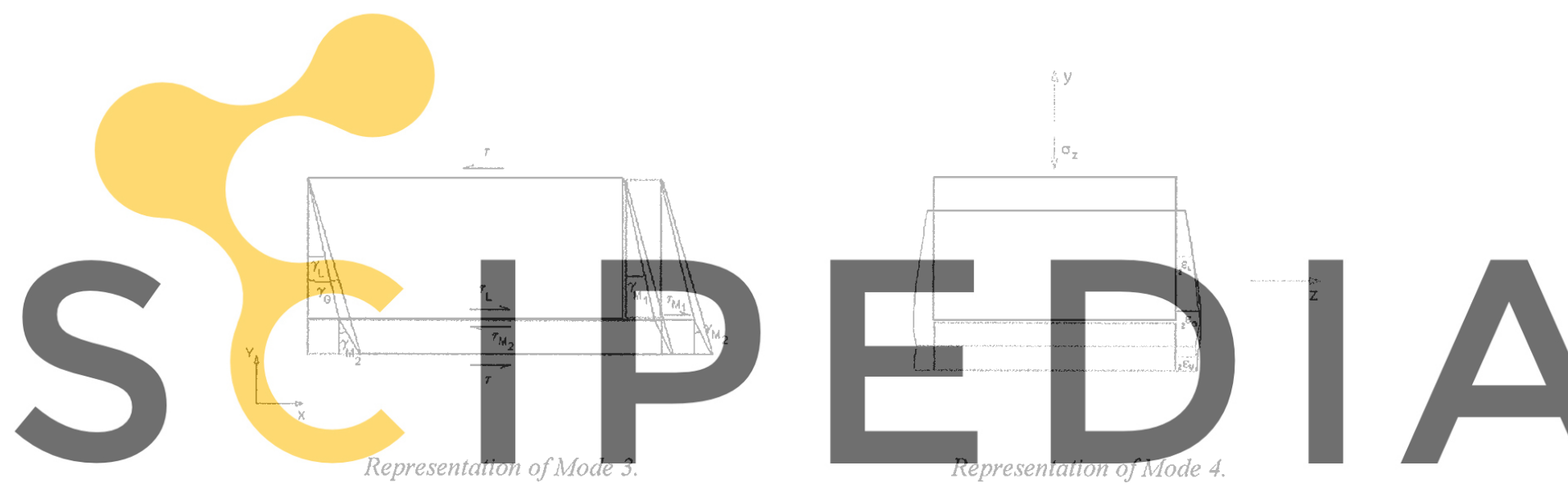

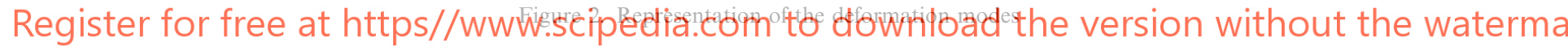

\subsubsection{Compatibility condition}

$$
\begin{aligned}
& { }_{x} \dot{\varepsilon}_{\mathrm{G}} l_{\mathrm{G}}={ }_{x} \dot{\varepsilon}_{\mathrm{M}_{2}} l_{\mathrm{M}_{2}} \\
& { }_{x} \dot{\varepsilon}_{G} l_{\mathrm{G}}={ }_{x} \dot{\varepsilon}_{\mathrm{L}} l_{\mathrm{L}}+{ }_{x} \dot{\varepsilon}_{\mathrm{M}_{1}} l_{\mathrm{M}_{1}}
\end{aligned}
$$

${ }_{i} \varepsilon_{j}$ represents the homogeneous strain in the ' $i$ ' direction of material with ' $j$ ' component, $l_{i}$ represents the length of ' $i$ ' material component.

\subsubsection{Constitutive equation (for each material component)}

$$
\begin{aligned}
& { }_{x} \dot{\sigma}_{i}={ }_{x} E_{i}\left(\omega_{i}\right)\left({ }_{x} \dot{\varepsilon}_{i}-{ }_{x} \dot{\varepsilon}_{i}^{\mathrm{p}}\right) \\
& { }_{x} \dot{\varepsilon}_{i}=\frac{{ }_{x} \dot{\sigma}_{i}}{{ }_{x} E_{i}\left(\omega_{i}\right)}+{ }_{x} \dot{\varepsilon}_{i}^{\mathrm{p}}
\end{aligned}
$$

In equation (3) we can see that the Young's modulus depends on the damage parameter $\omega$ due to the fact that the elastic modulus changes its value when the elastic limit is exceeded. In materials with softening (geomaterials for example), the value of $E$ decreases. 
4.1.4. Stress determination for each material component. Substituting (1) in (3) and then in (2), one obtains

$$
\begin{gathered}
{ }_{x} \sigma_{\mathrm{M}_{2}}={ }_{x} \sigma \frac{h_{\mathrm{G}}}{h_{\mathrm{M}_{2}}}-{ }_{x} \sigma_{\mathrm{L}} \frac{h_{\mathrm{L}}}{h_{\mathrm{M}_{2}}} \Rightarrow{ }_{x} \dot{\sigma}_{\mathrm{M}_{2}}={ }_{x} \dot{\sigma} \frac{h_{\mathrm{G}}}{h_{\mathrm{M}_{2}}}-{ }_{x} \dot{\sigma}_{\mathrm{L}} \frac{h_{\mathrm{L}}}{h_{\mathrm{M}_{2}}} \\
{ }_{x} \dot{\bar{\varepsilon}}_{\mathrm{M}_{2}}=\frac{{ }_{x} \sigma}{{ }_{x} E_{\mathbf{M}_{2}}} \frac{h_{\mathrm{G}}}{h_{\mathbf{M}_{2}}}-\frac{{ }_{x} \dot{\sigma}_{\mathrm{L}}}{{ }_{x} E_{\mathrm{M}_{2}}} \frac{h_{\mathrm{L}}}{h_{\mathrm{M}_{2}}}+{ }_{x} \dot{\dot{\varepsilon}_{\mathrm{M}_{2}}}{ }^{\mathrm{p}}
\end{gathered}
$$

The global deformation results from equation (2):

$$
\begin{aligned}
& { }_{x} \dot{\varepsilon}_{\mathrm{G}} l_{\mathrm{G}}=\frac{{ }_{x} \dot{\sigma}}{{ }_{x} E_{\mathrm{M}_{2}}} \frac{h_{\mathrm{G}}}{h_{\mathrm{M}_{2}}} l_{\mathrm{M}_{2}}-\frac{{ }_{x} \dot{\sigma}_{\mathrm{L}}}{{ }_{x} E_{\mathrm{M}_{2}}} \frac{h_{\mathrm{L}}}{h_{\mathrm{M}_{2}}} l_{\mathrm{M}_{2}}+{ }_{x} \dot{\varepsilon}_{\mathrm{M}_{2}} l_{\mathrm{M}_{2}}
\end{aligned}
$$

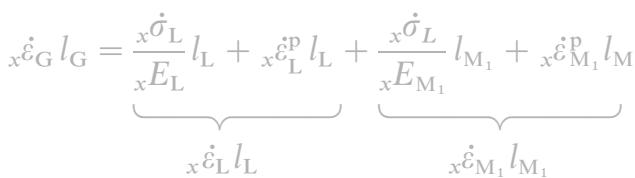

From expressions (4) and (5) results the rate of the stress in the brick material
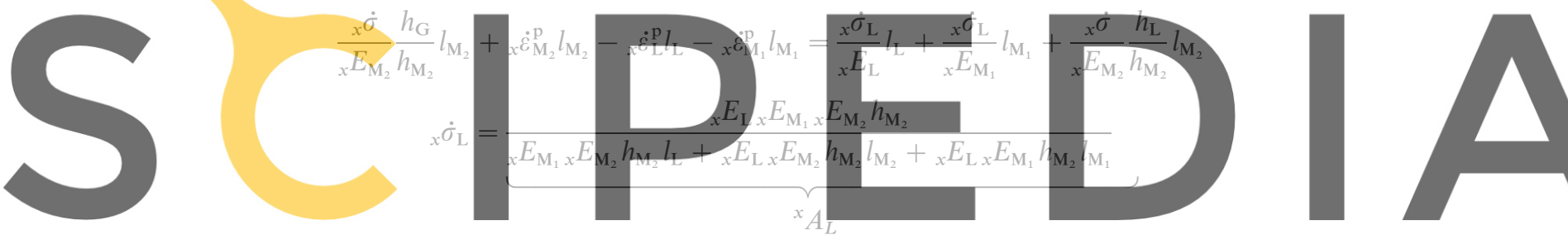

Register for free at https//www.

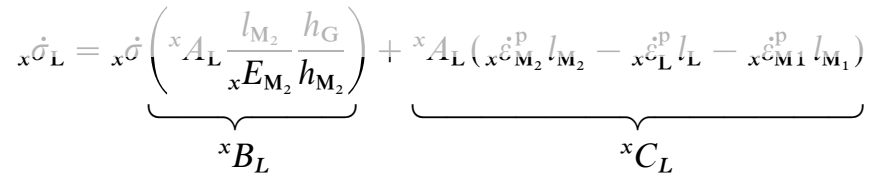

$$
\begin{aligned}
& { }_{x} \dot{\sigma}_{L}={ }_{x} \dot{\sigma}^{x} B_{\mathrm{L}}+{ }^{x} \dot{C}_{\mathrm{L}} \equiv{ }_{x} \dot{\sigma}_{M_{1}}
\end{aligned}
$$

From (1) there results the temporal variation of stress in mortar 2:

$$
\begin{aligned}
& { }_{x} \dot{\sigma}_{\mathrm{M}_{2}}={ }_{x} \dot{\sigma} \frac{h_{\mathrm{G}}}{h_{\mathrm{M}_{2}}}-{ }_{x} \dot{\sigma}_{L} \frac{h_{\mathrm{L}}}{h_{\mathrm{M}_{2}}}={ }_{x} \dot{\sigma} \frac{h_{\mathrm{G}}}{h_{\mathrm{M}_{2}}}-{ }^{x} \dot{\sigma}_{x} B_{\mathrm{L}} \frac{h_{\mathrm{L}}}{h_{\mathrm{M}_{2}}}-{ }^{x} \dot{C}_{\mathrm{L}} \frac{h_{\mathrm{L}}}{h_{\mathrm{M}_{2}}} \\
& { }_{x} \dot{\sigma}_{\mathrm{M}_{2}}={ }_{x} \dot{\sigma}{ }_{{ }^{x} B_{\mathrm{M}_{2}}}^{\left(\frac{h_{\mathrm{G}}-{ }^{x} B_{\mathrm{L}} h_{\mathrm{L}}}{h_{\mathrm{M}_{2}}}\right)}-\underbrace{{ }_{x} \dot{\sigma}_{\mathrm{M}_{2}}={ }_{x} \dot{\sigma}^{x} B_{\mathrm{M}_{2}}-{ }^{x} \dot{C}_{\mathrm{M}_{2}}}_{{ }^{x} C_{\mathrm{M}_{2}} \dot{C}_{\mathrm{L}} \cdot \frac{h_{\mathrm{L}}}{h_{\mathrm{M}_{2}}}}
\end{aligned}
$$


4.1.5. Determination of global constitutive law for each material component. From (5) one obtains

$$
\begin{aligned}
& { }_{x} \dot{\varepsilon}_{\mathrm{G}}=\frac{{ }_{x} \dot{\sigma}}{{ }_{x} E_{\mathrm{L}}} \frac{l_{\mathrm{L}}}{l_{\mathrm{G}}}+{ }_{x} \dot{\varepsilon}_{\mathrm{L}}^{\mathrm{p}} \frac{l_{\mathrm{L}}}{l_{\mathrm{G}}}+\frac{{ }_{x} \dot{\sigma}_{\mathrm{L}}}{{ }_{x} E_{\mathrm{M}_{1}}} \frac{l_{\mathrm{M}_{1}}}{l_{\mathrm{G}}}+{ }_{x} \dot{\varepsilon}_{\mathrm{B}_{1}}^{\mathrm{p}} \frac{l_{\mathrm{M}_{1}}}{l_{\mathrm{G}}} \\
& { }_{x} \dot{\varepsilon}_{\mathrm{G}}={ }_{x} \dot{\sigma}_{\mathrm{L}} \underbrace{\left(\frac{1}{{ }_{x} E_{\mathrm{L}}} \frac{l_{\mathrm{L}}}{l_{\mathrm{G}}}+\frac{1}{{ }_{x} E_{\mathrm{M}_{1}}} \frac{l_{\mathrm{M}_{1}}}{l_{\mathrm{G}}}\right)}_{{ }^{x} D}+\underbrace{\underbrace{}_{{ }_{\mathrm{G}}}}_{{ }_{x} \dot{\varepsilon}_{\mathrm{E}}^{\mathrm{p}} \frac{l_{\mathrm{L}}}{l_{\mathrm{G}}}+{ }_{x} \dot{\varepsilon}_{\mathrm{M}_{1}} \frac{l_{\mathrm{M}_{1}}}{l_{\mathrm{G}}}}
\end{aligned}
$$

\section{Replacing ${ }_{x} \dot{\sigma}_{\mathrm{L}}$ with its expression results in}

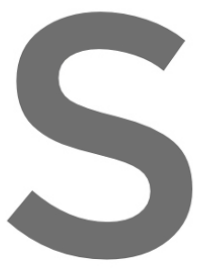

$$
\begin{aligned}
{ }_{x} \dot{\varepsilon}_{\mathrm{G}} & =\left({ }_{x} \dot{\sigma}^{x} B_{\mathrm{L}}+{ }^{x} \dot{C}_{\mathrm{L}}\right){ }^{x} D+{ }^{x} \dot{E} \\
{ }_{x} \dot{\varepsilon}_{\mathrm{G}} & =\left({ }_{x} \dot{\sigma}^{x} B_{\mathrm{L}}+{ }^{x} D\right)+\left({ }^{x} \dot{C}_{\mathrm{L}}{ }^{x} D+{ }^{x} \dot{E}\right)
\end{aligned}
$$

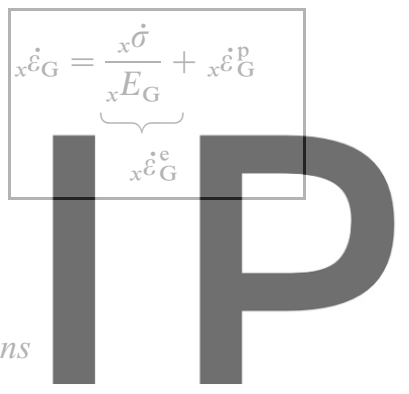

$$
\frac{1}{{ }_{x} E_{\mathrm{G}}}={ }^{x} B_{\mathrm{L}}{ }^{x} D
$$
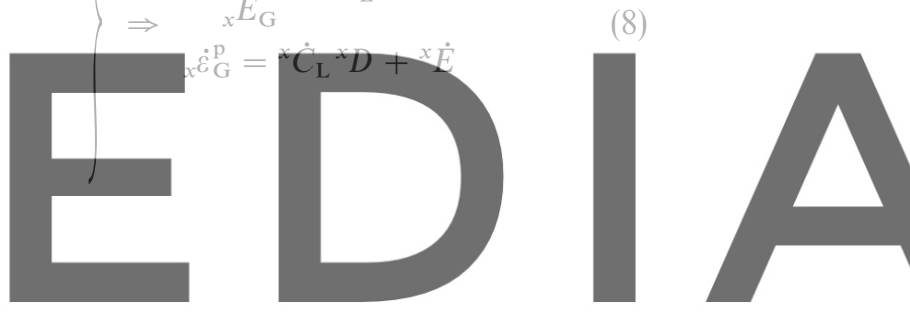

Mode 2 is defined as corresponding to a tension-compression stress in the $y$-direction.

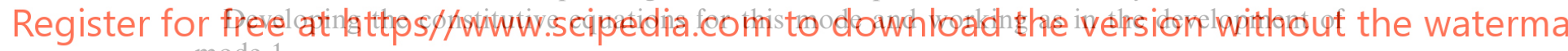
mode 1 .

\subsubsection{Equilibrium conditions}

$$
\begin{aligned}
{ }_{y} \sigma l_{\mathrm{G}} & ={ }_{y} \sigma_{\mathrm{L}} \cdot l_{\mathrm{L}}+{ }_{y} \sigma_{\mathrm{M}_{1}} l_{\mathrm{M}_{1}}={ }_{y} \sigma_{\mathrm{M}_{2}} l_{\mathrm{M}_{2}} \\
l_{\mathrm{M}_{2}} & =l_{\mathrm{G}} \Rightarrow{ }_{y} \sigma \equiv{ }_{y} \sigma_{\mathrm{M}_{2}} \\
{ }_{y} \sigma & ={ }_{y} \sigma_{\mathrm{L}} \cdot \frac{l_{\mathrm{L}}}{l_{\mathrm{G}}}+{ }_{y} \sigma_{M_{1}} \cdot \frac{l_{\mathrm{M}_{1}}}{l_{\mathrm{G}}} \\
{ }_{y} \sigma & ={ }_{y} \sigma_{\mathrm{M}_{1}}
\end{aligned}
$$

where ${ }_{i} \sigma_{j}$ represents a homogeneous ' $i$ '-stress state of the ' $j$ ' material component, $l_{i}$ represents the length of the ' $i$ ' material component.

\subsubsection{Compatibility condition}

$$
\begin{aligned}
& { }_{y} \dot{\varepsilon}_{\mathrm{G}} h_{\mathrm{G}}={ }_{y} \dot{\varepsilon}_{\mathrm{L}} h_{\mathrm{L}}+{ }_{y} \dot{\varepsilon}_{\mathrm{M}_{2}} h_{\mathrm{M}_{2}} \\
& { }_{y} \dot{\varepsilon}_{G} h_{\mathrm{G}}={ }_{y} \dot{\varepsilon}_{\mathrm{M}_{1}} h_{\mathrm{M}_{1}}+{ }_{y} \dot{\varepsilon}_{\mathrm{M}_{2}} h_{\mathrm{M}_{2}}
\end{aligned}
$$

${ }_{i} \varepsilon_{j}$ represents the homogeneous strain in the ' $i$ ' direction of material ' $j$ ', $h_{i}$ represents the height of the ' $i$ ' material component. 
4.2.3. Constitutive equation (for each material component)

$$
\begin{aligned}
& { }_{y} \dot{\sigma}_{i}={ }_{y} E_{i}\left(\omega_{i}\right)\left({ }_{y} \dot{\varepsilon}_{i}-{ }_{y} \dot{\varepsilon}_{i}^{\mathrm{p}}\right) \\
& { }_{y} \dot{\varepsilon_{i}}=\frac{{ }_{y} \dot{\sigma}_{i}}{{ }_{y} E_{i}\left(\omega_{i}\right)}+{ }_{y} \dot{\varepsilon}_{i}^{\mathrm{p}}
\end{aligned}
$$

As with the previous mode, the Young's modulus is assumed dependent of the damage parameter $\omega$.

4.2.4. Stress determination for each material component. In the same way as for mode 1 , we obtain the brick stress as

$$
{ }_{y} \dot{\sigma}_{\mathrm{L}}={ }_{y} \dot{\sigma}^{y} B_{\mathrm{L}}+{ }^{y} \dot{C}_{\mathrm{L}}
$$

with
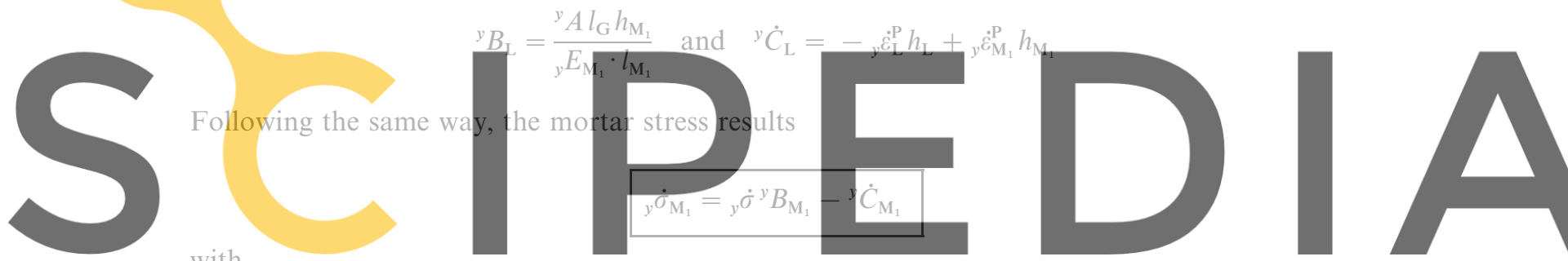

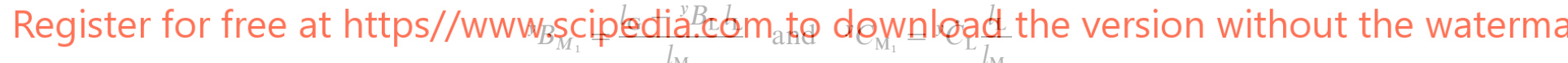

For equiliorium conditions their results:

$$
{ }_{y} \dot{\sigma}_{\mathrm{M}_{2}}={ }_{y} \dot{\sigma}
$$

4.2.5. Determination of global constitutive law for each material component

$$
\begin{aligned}
& \dot{\varepsilon}_{\mathrm{G}}={ }_{y} \dot{\varepsilon}_{\mathrm{L}} \frac{h_{\mathrm{L}}}{h_{\mathrm{G}}}+{ }_{y} \dot{\varepsilon}_{\mathrm{M}_{2}} \frac{h_{\mathrm{M}_{2}}}{h_{\mathrm{G}}} \\
& \dot{\varepsilon}_{y}=\left(\frac{{ }_{y} \dot{\sigma}_{\mathrm{L}}}{{ }_{y} E_{\mathrm{L}}}+{ }_{y} \dot{\varepsilon}_{\mathrm{L}}^{\mathrm{p}}\right) \frac{\dot{h}_{\mathrm{L}}}{h_{\mathrm{G}}}+\left(\frac{{ }_{y} \dot{\sigma}_{\mathrm{M}_{2}}}{{ }_{y} E_{\mathrm{M}_{2}}}+{ }_{y} \dot{\varepsilon}_{\mathrm{L}}^{\mathrm{p}}\right) \frac{h_{\mathrm{M}_{2}}}{h_{\mathrm{G}}} \\
& \dot{y}_{y}=\frac{{ }_{y} \dot{\sigma}_{\mathrm{L}}}{{ }_{y} E_{\mathrm{L}}} \frac{h_{\mathrm{L}}}{h_{\mathrm{G}}}+{ }_{y} \dot{\varepsilon}_{\mathrm{L}}^{\mathrm{p}} \frac{h_{\mathrm{L}}}{h_{\mathrm{G}}}+\frac{{ }_{y} \dot{\sigma}_{\mathrm{M}_{2}}}{{ }_{y} E_{\mathrm{M}_{2}}} \frac{h_{\mathrm{M}_{2}}}{h_{\mathrm{G}}}+{ }_{y} \dot{\varepsilon}_{\mathrm{M}_{2}} \frac{h_{\mathrm{M}_{2}}}{h_{\mathrm{G}}} \\
& \dot{y}_{y}=\left({ }_{y} \dot{\sigma}^{y} B_{\mathrm{L}}+{ }^{y} \dot{C}_{\mathrm{L}}\right) \frac{h_{\mathrm{L}}}{{ }_{y} E_{\mathrm{L}} h_{\mathrm{G}}}+\frac{{ }_{y} \dot{\sigma} h_{\mathrm{M}_{2}}}{E_{\mathrm{M}_{2}} h_{\mathrm{G}}}+{ }_{y} \dot{\varepsilon}_{\mathrm{L}} \frac{h_{\mathrm{L}}}{h_{\mathrm{G}}}+{ }_{y} \dot{\varepsilon}_{\mathrm{M}_{2}} \frac{h_{\mathrm{M}_{2}}}{h_{\mathrm{G}}}
\end{aligned}
$$

Copyright (C) 1999 John Wiley \& Sons, Ltd.

Int. J. Numer. Meth. Engng. 46, 1651-1671 (1999) 


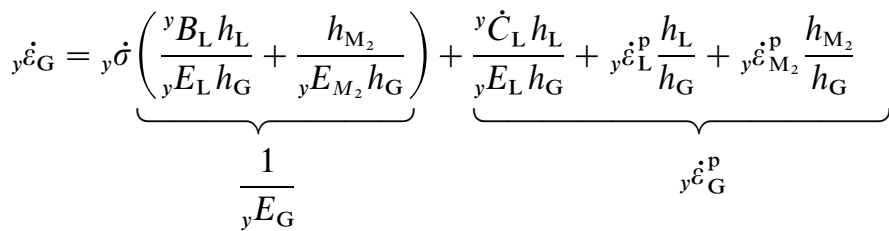

$$
\begin{aligned}
& { }_{y} \dot{\varepsilon}_{\mathrm{G}}=\frac{{ }_{y} \dot{\sigma}}{{ }_{y} E_{\mathrm{G}}}+{ }_{y} \dot{\varepsilon}_{\mathrm{G}}^{\mathrm{p}}
\end{aligned}
$$

\subsection{Mode 3 equations}

The third mode corresponds to shear deformation in the $X Y$ plane. While in fact brick and mortar have different deformations due to their different geometrical and mechanical properties, the present formulation requires them to have the same deformation governed by the straight line that homogenizes this behaviour (see the figure for Mode 3 in Figure 2).

\section{As in the two previous modes, there results:}
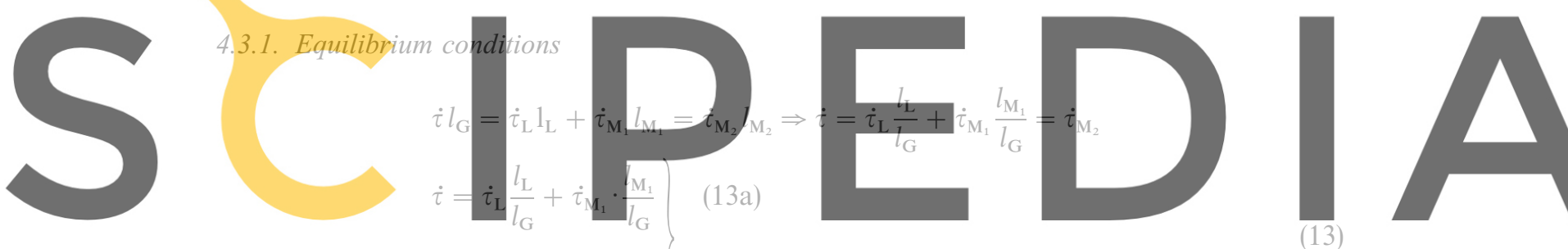

Register for free at https $/ / \bar{W} \dot{\tau}_{W}$ w.scipedia.com to download the version without the waterma

where $\tau_{i}$ represents the shear stress in the $X Y$ plane in the ' $i$ ' material component.

\subsubsection{Compatibility condition. Assuming that}

$$
{ }_{x y} \gamma_{\mathrm{M}_{1}}={ }_{x y} \gamma_{\mathrm{L}}, \quad h_{\mathrm{M}_{1}}=h_{\mathrm{L}}
$$

where ${ }_{x y} \gamma_{j}$ represents the shear strain in $X Y$ plane of ' $j$ ' material component.

Applying displacement compatibility and assuming the previous hypothesis results in the brick strain and the mortar 1 strain:

$$
{ }_{x y} \dot{\gamma}_{\mathrm{M}_{1}} h_{\mathrm{M}_{1}}={ }_{x y} \dot{\gamma}_{\mathrm{L}} h_{\mathrm{L}} \Rightarrow{ }_{x y} \dot{\gamma}_{\mathrm{M}_{1}}={ }_{x y} \dot{\gamma}_{\mathrm{L}}
$$

this verifies that brick strain and mortar 1 strain are the same.

$$
\begin{aligned}
& { }_{x y} \dot{\gamma}_{\mathrm{M}_{1}}^{\mathrm{e}}={ }_{x y} \dot{\gamma}_{\mathrm{M}_{1}}-{ }_{x y} \dot{\gamma}_{\mathrm{M}_{1}}^{\mathrm{p}}={ }_{x y} \dot{\gamma}_{\mathrm{L}}-{ }_{x y} \dot{\gamma}_{\mathrm{M}_{1}}^{\mathrm{p}}=\left({ }_{x y} \dot{\gamma}_{\mathrm{L}}^{\mathrm{e}}+{ }_{x y} \dot{\gamma}_{\mathrm{L}}^{\mathrm{p}}\right)-{ }_{x y} \dot{\gamma}_{\mathrm{M}_{1}}^{\mathrm{p}} \\
& \dot{\tau}_{\mathrm{M}_{1}}={ }_{x y} G_{\mathrm{M}_{1} x y} \dot{\gamma}_{\mathrm{M}_{1}}^{\mathrm{e}}={ }_{x y} G_{\mathrm{M}_{1}}\left(\frac{\dot{\tau}_{\mathrm{L}}}{{ }_{x y} G_{\mathrm{L}}}+{ }_{x y} \dot{\gamma}_{\mathrm{L}}^{\mathrm{p}}-{ }_{x y} \dot{\gamma}_{\mathrm{M}_{1}}^{\mathrm{p}}\right) \\
& \dot{\tau}_{\mathrm{M}_{1}}=\dot{\tau}_{\mathrm{L}} \frac{{ }_{x y} G_{\mathrm{M}_{1}}}{{ }_{x y} G_{\mathrm{L}}}+{ }_{x y} G_{\mathrm{M}_{1}}\left({ }_{x y} \dot{\gamma}_{\mathrm{L}}^{\mathrm{p}}-{ }_{x y} \dot{\gamma}_{\mathrm{M}_{1}}^{\mathrm{p}}\right)
\end{aligned}
$$


4.3.3. Constitutive equation (for each material component). Substituting (14) in (13a) results in the temporal variation of stress in the brick

$$
\begin{aligned}
& \dot{\tau}=\dot{\tau}_{\mathrm{L}} \frac{l_{\mathrm{L}}}{l_{\mathrm{G}}}+\dot{\tau}_{\mathrm{L}} \frac{{ }_{x y} G_{\mathrm{M}_{1}} G_{\mathrm{L}}}{l_{\mathrm{G}}}+{ }_{x y} G_{\mathrm{M}_{1}} \frac{l_{\mathrm{M}_{1}}}{l_{\mathrm{G}}}\left({ }_{x y} \dot{\gamma}_{\mathrm{L}}^{\mathrm{p}}-{ }_{x y} \dot{\gamma}_{\mathrm{M}_{1}}^{\mathrm{p}}\right) \equiv \dot{\tau}_{\mathrm{M}_{2}} \\
& \dot{\tau}=\dot{\tau}_{\mathrm{L}}\left(\frac{l_{\mathrm{L}}}{l_{\mathrm{G}}}+\frac{{ }_{x y} G_{\mathrm{M}_{1}}}{{ }_{x y} G_{\mathrm{L}}} \frac{l_{\mathrm{M}_{1}}}{l_{\mathrm{G}}}\right)+{ }_{x y} G_{\mathrm{M}_{1}} \frac{l_{\mathrm{M}_{1}}}{l_{\mathrm{G}}}\left({ }_{x y} \dot{\gamma}_{\mathrm{L}}^{\mathrm{p}}-{ }_{x y} \dot{\gamma}_{\mathrm{M}_{1}}^{\mathrm{p}}\right)
\end{aligned}
$$
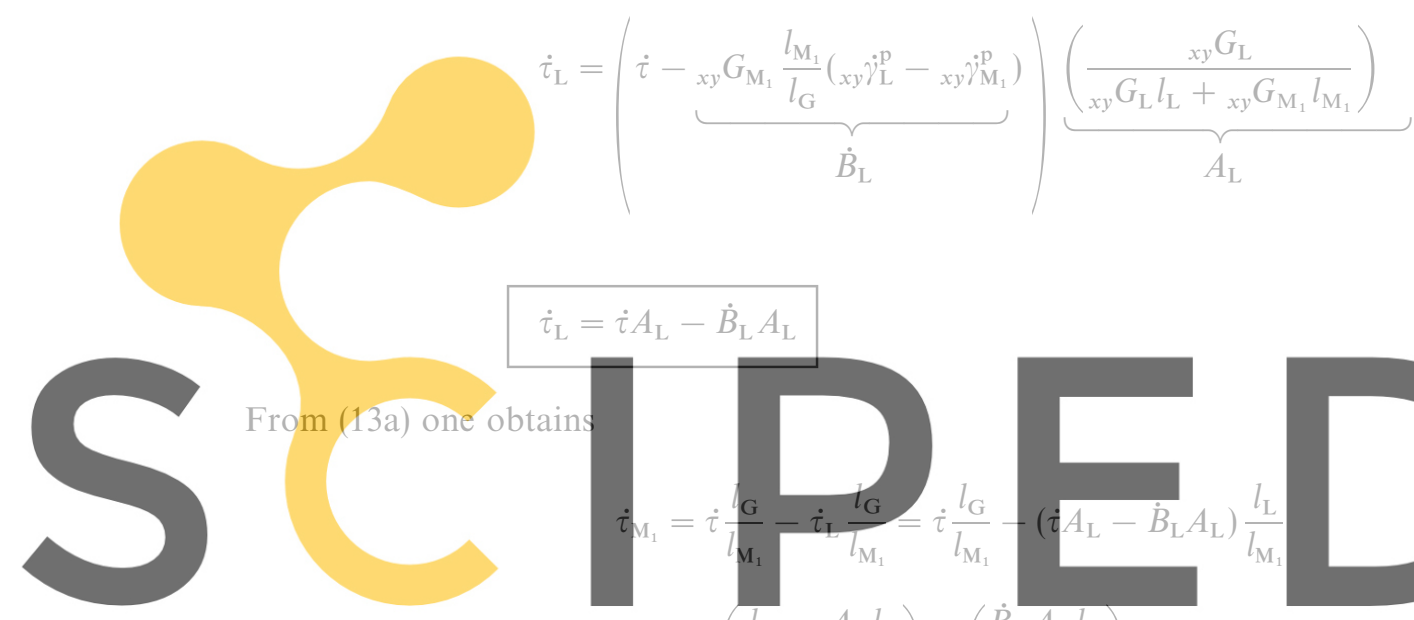

$$
\dot{\tau}_{\mathrm{L}}=\dot{\tau} A_{\mathrm{L}}-\dot{B}_{\mathrm{L}} A_{\mathrm{L}}
$$

$$
\dot{\tau}_{\mathrm{M}_{1}}=\dot{\tau} A_{M_{1}}-\dot{B}_{\mathrm{M}_{1}}
$$

The last expression represents the rate of the stress in mortar 1.

4.3.4. Constitutive law

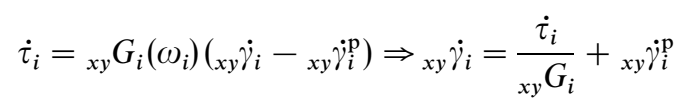

\subsubsection{Global compatibility equation for each element}

$$
\begin{aligned}
{ }_{x y} \dot{\gamma}_{\mathrm{G}} h_{\mathrm{G}} & =\left({ }_{x y} \dot{\gamma}_{\mathrm{L}} h_{\mathrm{L}}\right)+\left({ }_{x y} \dot{\gamma}_{\mathrm{M}_{2}} h_{\mathrm{M}_{2}}\right)=\left({ }_{x y} \dot{\gamma}_{\mathrm{M}_{1}} h_{\mathrm{M}_{1}}\right)+\left({ }_{x y} \dot{\gamma}_{\mathrm{M}_{2}} h_{\mathrm{M}_{2}}\right) \\
{ }_{x y} \dot{\gamma}_{\mathrm{G}} & =\left({ }_{x y} \dot{\gamma}_{\mathrm{L}} \frac{h_{\mathrm{L}}}{h_{\mathrm{G}}}\right)+\left({ }_{x y} \dot{\gamma}_{\mathrm{M}_{2}} \frac{h_{\mathrm{M}_{2}}}{h_{\mathrm{G}}}\right)
\end{aligned}
$$


Introducing the constitutive equation one obtains

$$
{ }_{x y} \dot{\gamma}_{\mathrm{G}}=i \frac{1}{{ }_{x y} G_{\mathrm{G}}}+{ }_{x y} \dot{\gamma}_{\mathrm{G}}^{\mathrm{p}}
$$

with

$$
{ }_{x y} G_{\mathrm{G}}=\left(\frac{A_{\mathrm{L}} h_{\mathrm{L}}}{{ }_{x y} G_{\mathrm{L}} h_{\mathrm{G}}}+\frac{h_{\mathrm{M}_{2}}}{{ }_{x y} G_{\mathrm{M}_{2}} h_{\mathrm{G}}}\right)^{-1} \text { and }{ }_{x y} \dot{\gamma}_{\mathrm{G}}^{\mathrm{p}}=\left(-\dot{B}_{\mathrm{L}} A_{\mathrm{L}} \frac{h_{\mathrm{L}}}{{ }_{x y} G_{\mathrm{L}} h_{\mathrm{G}}}+{ }_{x y} \dot{\gamma}_{\mathrm{L}}^{\mathrm{p}} \frac{h_{\mathrm{L}}}{h_{\mathrm{G}}}+{ }_{x y} \dot{\gamma}_{\mathrm{M}_{2}}^{\mathrm{p}} \frac{h_{\mathrm{M}_{2}}}{h_{\mathrm{G}}}\right)
$$

\subsection{Equations of mode 4}

The fourth deformation mode is the one which corresponds to the deformation field out of the plane of loading (plane $X Y$ ). Since in the model we accept the plane stress hypothesis, the deformations in the plane $X Z$ should be limited to deformations produced by the Poisson effect. Also, due to the fact that there are no external tangential actions associated with the planes $X Z$ and $Y Z$ (plane stress hypothesis), the resultants of the shear stresses $\tau_{x z}$ and $\tau_{y z}$ integrated for all the elements vanish. The associated distortions will be assumed to vanish.

From the figure for Mode 4 in Figure 2 it can be observed that the deformation experienced by brick and mortar describes a curve whose slope is discontinuous at the juncture between the two materials, due to the restriction imposed by the contact between two materials with different properties. In the homogenized model the envelope of the deformation curves has been adopted as representing the deformation.

In contrast to the procedure followed for the previous modes, in this case we will work implicitly with the equations in homogeneous variable terms, taking as starting point the expression of the Secant Constitutive Matrix in the case of orthotropy.

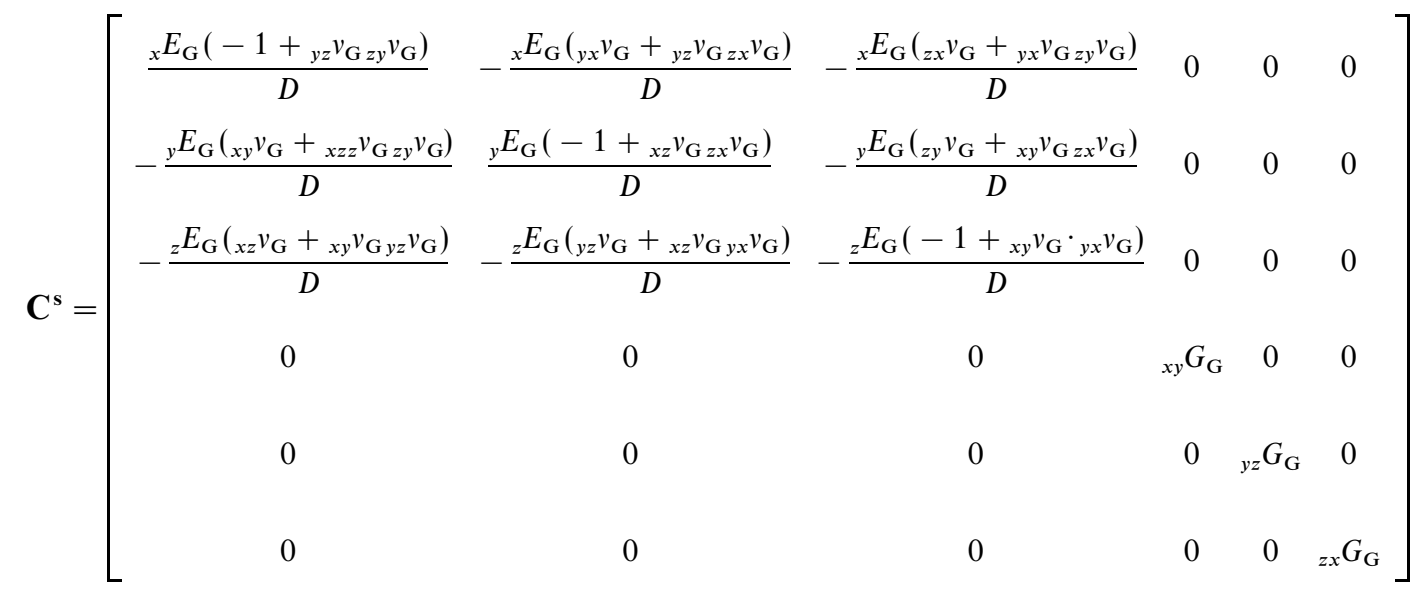

where

$$
\begin{aligned}
D & =-1+{ }_{x y} v_{\mathrm{G} y x} v_{\mathrm{G}}+{ }_{x z} v_{\mathrm{G} z x} v_{\mathrm{G}}+{ }_{y z} v_{\mathrm{G} z y} v_{\mathrm{G}}+{ }_{x y} v_{\mathrm{G} y z} v_{\mathrm{G} z x} v_{\mathrm{G}}+{ }_{x z} v_{\mathrm{G} y x} v_{\mathrm{G} z y} v_{\mathrm{G}} \\
\sigma_{\mathrm{G}} & =\mathbf{C}^{\mathrm{s}} \varepsilon_{\mathrm{G}}
\end{aligned}
$$


It must be pointed out that ${ }_{x} E_{\mathrm{G}},{ }_{y} E_{\mathrm{G}},{ }_{z} E_{\mathrm{G}},{ }_{x y} G_{\mathrm{G}},{ }_{z x} G_{\mathrm{G}},{ }_{y z} G_{\mathrm{G}}$ are obtained from the developments for the previous modes.

Isolating the $z$ component of ${ }_{z} \sigma_{\mathrm{G}}$ of the vector $\boldsymbol{\sigma}_{\mathrm{G}}$ and applying the plane stress hypothesis results in

$$
\begin{gathered}
\sigma_{z}=-\frac{E_{\mathrm{z}}}{D}\left({ }_{x z} v_{\mathrm{G}}+{ }_{x y} v_{\mathrm{G} y z} v_{\mathrm{G}}\right)_{x} \varepsilon_{\mathrm{G}}-\frac{E_{z}}{D}\left({ }_{y z} v_{\mathrm{G}}+{ }_{x z} v_{\mathrm{G} y x} v_{\mathrm{G}}\right)_{y} \varepsilon_{\mathrm{G}}+\frac{E_{z}}{D}\left(-1+{ }_{x y} v_{\mathrm{G} y x} v_{\mathrm{G}}\right)_{z} \varepsilon_{\mathrm{G}}=0 \\
\sigma_{z}=\frac{E_{z}}{D}\left[-\left({ }_{x z} v_{\mathrm{G}}+{ }_{x y} v_{\mathrm{G} y z} v_{\mathrm{G}}\right)_{x} \varepsilon_{\mathrm{G}}-\left({ }_{y z} v_{\mathrm{G}}+{ }_{x z} v_{\mathrm{G} y x} v_{\mathrm{G}}\right)_{y} \varepsilon_{\mathrm{G}}+\left(-1+{ }_{x y} v_{\mathrm{G} y x} v_{\mathrm{G}}\right)_{z} \varepsilon_{\mathrm{G}}\right]=0 \\
{ }_{z} \varepsilon_{\mathrm{G}}={ }_{z} \varepsilon_{\mathrm{G}}^{\mathrm{e}}+{ }_{z} \varepsilon_{\mathrm{G}}^{\mathrm{p}}=\frac{\left({ }_{x z} v_{\mathrm{G}}+{ }_{x y} v_{\mathrm{G} y z} v_{\mathrm{G}}\right)_{z} \varepsilon_{\mathrm{G}}+\left({ }_{y z} v_{\mathrm{G}}+{ }_{x z} v_{\mathrm{G} y x} v_{\mathrm{G}}\right)_{y} \varepsilon_{\mathrm{G}}}{\left(-1+{ }_{x y} v_{\mathrm{G} y x} v_{\mathrm{G}}\right)} \\
{ }_{z} \varepsilon_{\mathrm{G}}={ }_{z} \varepsilon_{\mathrm{G}}^{\mathrm{e}}+{ }_{z} \varepsilon_{\mathrm{G}}^{\mathrm{p}}=\frac{\left({ }_{x z} v_{\mathrm{G}}+{ }_{x y} v_{\mathrm{G} y z} v_{\mathrm{G}}\right)\left({ }_{x} \varepsilon_{\mathrm{G}}^{\mathrm{e}}+{ }_{x} \varepsilon_{\mathrm{G}}^{\mathrm{p}}\right)+\left({ }_{y z} v_{\mathrm{G}}+{ }_{x z} v_{\mathrm{G} y x} v_{\mathrm{G}}\right)\left({ }_{y} \varepsilon_{\mathrm{G}}{ }^{\mathrm{e}}+{ }_{y} \varepsilon_{\mathrm{G}}^{\mathrm{p}}\right)}{\left(-1+{ }_{x y} v_{\mathrm{G} y x} v_{\mathrm{G}}\right)}
\end{gathered}
$$

By separating the elastic and plastic components in this expression we obtain the elastic and plastic global strains in the $Z$ direction:

$$
\begin{aligned}
& { }_{z} \varepsilon_{\mathrm{G}}^{\mathrm{e}}=\frac{\left({ }_{x z} v_{\mathrm{G}}+{ }_{x y} v_{\mathrm{G} y z} v_{\mathrm{G}}\right)_{x} \varepsilon_{\mathrm{G}}^{\mathrm{e}}+\left({ }_{y z} v_{\mathrm{G}}+{ }_{x z} v_{\mathrm{G} y x} v_{\mathrm{G}}\right)_{y} \varepsilon_{\mathrm{G}}^{\mathrm{e}}}{\left(-1+{ }_{x y} v_{\mathrm{G} y x} v_{\mathrm{G}}\right)} \\
& { }_{z} \varepsilon_{\mathrm{G}}^{\mathrm{p}}=\frac{\left({ }_{x z} v_{\mathrm{G}}+{ }_{x y} v_{\mathrm{G} y z} v_{\mathrm{G}}\right)_{x} \varepsilon_{\mathrm{G}}^{\mathrm{p}}+\left({ }_{y z} v_{\mathrm{G}}+{ }_{x z} v_{\mathrm{G} y x} v_{\mathrm{G}}\right)_{y} \varepsilon_{\mathrm{G}}^{\mathrm{p}}}{\left(-1+{ }_{x y} v_{\mathrm{G} y x} v_{\mathrm{G}}\right)}
\end{aligned}
$$

\subsection{Calculation of the homogeneous mechanical parameters}

From the development of the constitutive model the values of the homogeneous mechanical parameters of the masonry have been obtained. From the results presented their sensitivity to the dimensions of the component elements (bricks and joints of mortar) can be observed.

In order to be consistent in the notation, the different geometric parameters of the model that are used are presented in Figure 3.

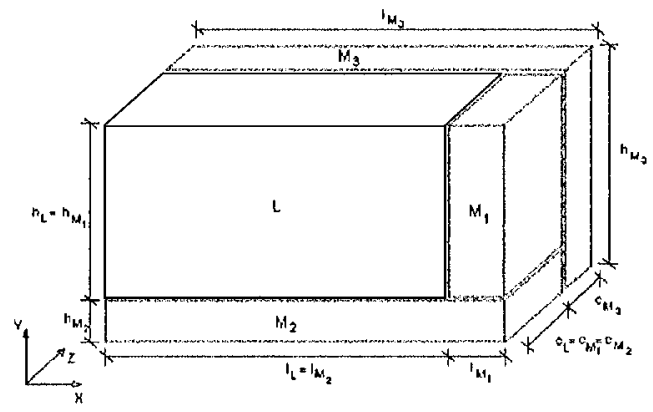

Figure 3. Geometrical three-dimensional representation of a masonry element 
Below we go on to find the expressions of the mechanical parameters in explicit form from the constitutive model.

From expression (8) the longitudinal elastic modulus in the global $X$ direction is obtained

$$
{ }_{x} E_{\mathrm{G}}=\frac{1}{{ }^{x} B_{\mathrm{L}}{ }^{x} D}
$$

where

and

$$
{ }^{x} D=\frac{l_{\mathrm{L}}}{{ }_{x} E_{\mathrm{L}} l_{\mathrm{G}}}+\frac{l_{\mathrm{M}_{1}}}{{ }_{x} E_{\mathrm{M}_{1}} l_{\mathrm{G}}}, \quad{ }^{x} B_{L}=\frac{{ }^{x} A_{\mathrm{L}} l_{\mathrm{M}_{2}} h_{\mathrm{G}}}{{ }_{x} E_{\mathrm{M}_{2}} h_{\mathrm{M}_{2}}}
$$

$$
{ }^{x} A_{\mathrm{L}}=\frac{{ }_{x} E_{\mathrm{L} x} E_{\mathrm{M}_{1} x} E_{\mathrm{M}_{2}} h_{\mathrm{M}_{1}}}{{ }_{x} E_{\mathrm{M}_{1} x} E_{\mathrm{M}_{2}} h_{\mathrm{M}_{2}} l_{\mathrm{L}}+{ }_{x} E_{\mathrm{L} x} E_{\mathrm{M}_{2}} h_{\mathrm{M}_{2}} l_{\mathrm{M}_{1}}+{ }_{x} E_{\mathrm{L} x} E_{\mathrm{M}_{1}} h_{\mathrm{L}} l_{\mathrm{M}_{2}}}
$$

From expression (12) the longitudinal elastic modulus in the global $Y$ direction is obtained

$$
{ }_{y} E_{\mathrm{G}}=\frac{1}{\left({ }^{y} B_{\mathrm{L}} h_{L}\right) /\left({ }_{y} E_{\mathrm{L}} h_{\mathrm{G}}\right)+h_{\mathrm{M}_{2}} /\left({ }_{y} E_{\mathrm{M}_{2}} h_{\mathrm{G}}\right)}
$$

where

$$
{ }^{y} B_{\mathrm{L}}=\frac{{ }^{y} A_{\mathrm{L}} l_{\mathrm{G}} h_{\mathrm{M}_{1}}}{{ }_{y} E_{\mathrm{M}_{1}} h_{\mathrm{M}_{1}}} \quad \text { and } \quad{ }^{x} A_{\mathrm{L}}=\frac{{ }_{y} E_{\mathrm{L} y} E_{\mathrm{M}_{1}} l_{\mathrm{M}_{1}}}{{ }_{x} E_{\mathrm{M}_{1}} l_{\mathrm{M}_{1}} h_{\mathrm{L}}+{ }_{x} E_{\mathrm{L}} l_{\mathrm{L}} h_{\mathrm{M}_{1}}}
$$

In the case of ${ }_{z} E_{\mathrm{G}}$, since the behaviour is just as in the case of mode 1 , the longitudinal elastic modulus in the global $Z$ direction is obtained

$$
{ }_{z} E_{\mathrm{G}}=\frac{1}{{ }^{z} B_{\mathrm{L}}{ }^{z} D}
$$

where

and

$$
{ }^{z} D=\frac{c_{\mathrm{L}}}{{ }_{z} E_{\mathrm{L}} c_{\mathrm{G}}}+\frac{c_{\mathrm{M}_{1}}}{{ }_{z} E_{\mathrm{M}_{1}} c_{\mathrm{G}}}, \quad{ }^{z} B_{\mathrm{L}}=\frac{{ }^{z} A_{\mathrm{L}} c_{\mathrm{M}_{2}} h_{\mathrm{G}}}{{ }_{z} E_{\mathrm{M}_{2}} h_{\mathrm{M}_{2}}}
$$

$$
{ }^{z} A_{\mathrm{L}}=\frac{{ }_{x} E_{\mathrm{L} x} E_{\mathrm{M}_{1} x} E_{\mathrm{M}_{2}} h_{\mathrm{M}_{1}}}{{ }_{x} E_{\mathrm{M}_{1} x} E_{\mathrm{M}_{2}} h_{\mathrm{M}_{2}} c_{\mathrm{L}}+{ }_{x} E_{\mathrm{L} x} E_{\mathrm{M}_{2}} h_{\mathrm{M}_{2}} c_{\mathrm{M}_{3}}+{ }_{x} E_{\mathrm{L} x} E_{\mathrm{M}_{1}} h_{\mathrm{L}} c_{\mathrm{M}_{2}}}
$$

From expression (17) the shear modulus in the global $X Y$ plane is obtained

$$
{ }_{x y} G_{\mathrm{G}}=\frac{1}{\left({ }^{x y} A_{\mathrm{L}} h_{\mathrm{L}}\right) /\left({ }_{x y} G_{\mathrm{L}} h_{\mathrm{G}}\right)+h_{\mathrm{M}_{2}} /\left({ }_{x y} G_{\mathrm{M}_{2}} h_{\mathrm{G}}\right)}
$$

where

$$
{ }^{x y} A_{\mathrm{L}}=\frac{{ }_{x y} G_{\mathrm{L}} l_{\mathrm{G}}}{x y G_{\mathrm{L}} l_{\mathrm{L}}+{ }_{x y} G_{\mathrm{M}_{1}} l_{\mathrm{M}_{1}}}
$$


Working in the same way for the remaining directions, we obtain the shear modulus in the global $Y X$ plane

$$
{ }_{y x} G_{\mathrm{G}}=\frac{1}{\left({ }^{y x} A_{\mathrm{L}} l_{\mathrm{L}}\right) /\left({ }_{y x} G_{\mathrm{L}} l_{\mathrm{G}}\right)+l_{\mathrm{M}_{2}} /\left({ }_{y x} G_{\mathrm{M}_{2}} l_{\mathrm{G}}\right)}
$$

where

$$
{ }^{y x} A_{\mathrm{L}}=\frac{{ }_{x y} G_{\mathrm{L}} h_{\mathrm{G}}}{{ }_{x y} G_{\mathrm{L}} h_{\mathrm{L}}+{ }_{x y} G_{\mathrm{M}_{1}} h_{\mathrm{M}_{2}}}
$$

Shear modulus in the global $X Z$ plane

$$
{ }_{x z} G_{\mathrm{G}}=\frac{1}{\left({ }^{x z} A_{\mathrm{L}} c_{\mathrm{L}}\right) /\left({ }_{x z} G_{\mathrm{L}} c_{\mathrm{G}}\right)+c_{\mathrm{M}_{3}} /\left({ }_{x z} G_{\mathrm{M}_{3}} c_{\mathrm{G}}\right)}
$$

where

$$
{ }^{x z} A_{L}=\frac{{ }_{x z} G_{\mathrm{L}} l_{\mathrm{G}}}{{ }_{x z} G_{\mathrm{L}} l_{\mathrm{L}}+{ }_{x z} G_{\mathrm{M}_{1}} l_{\mathrm{M}_{1}}}
$$

Shear modulus in the global $Z X$ plane

$$
{ }_{z x} G_{\mathrm{G}}=\frac{1}{\left({ }^{z x} A_{\mathrm{L}} l_{\mathrm{L}}\right) /\left({ }_{z x} G_{\mathrm{L}} l_{\mathrm{G}}\right)+l_{\mathrm{M}_{1}} /\left({ }_{z x} G_{\mathrm{M}_{1}} l_{\mathrm{G}}\right)}
$$

where

$$
{ }^{z x} A_{\mathrm{L}}=\frac{{ }_{z x} G_{\mathrm{L}} c_{\mathrm{G}}}{{ }_{z x} G_{\mathrm{L}} c_{\mathrm{L}}+{ }_{x z} G_{\mathrm{M}_{3}} c_{\mathrm{M}_{3}}}
$$

Shear modulus in the global $Z Y$ plane

$$
{ }_{z y} G_{\mathrm{G}}=\frac{1}{\left({ }^{z y} A_{\mathrm{L}} h_{\mathrm{L}}\right) /\left({ }_{z y} G_{\mathrm{L}} h_{\mathrm{G}}\right)+h_{\mathrm{M}_{2}} /\left({ }_{z y} G_{\mathrm{M}_{2}} h_{\mathrm{G}}\right)}
$$

where

$$
{ }^{z y} A_{L}=\frac{{ }_{z y} G_{\mathrm{L}} c_{\mathrm{G}}}{{ }_{z y} G_{\mathrm{L}} c_{\mathrm{L}}+{ }_{x y} G_{\mathrm{M}_{3}} c_{\mathrm{M}_{3}}}
$$

Shear modulus in the global $Y Z$ plane

$$
{ }_{y z} G_{\mathrm{G}}=\frac{1}{\left({ }^{y z} A_{\mathrm{L}} c_{\mathrm{L}}\right) /\left({ }_{y z} G_{\mathrm{L}} c_{\mathrm{G}}\right)+c_{\mathrm{M}_{3}} /\left({ }_{z x} G_{\mathrm{M}_{3}} c_{\mathrm{G}}\right)}
$$

where

$$
{ }^{y z} A_{\mathrm{L}}=\frac{{ }_{y z} G_{\mathrm{L}} h_{\mathrm{G}}}{{ }_{y z} G_{\mathrm{L}} h_{\mathrm{L}}+{ }_{y z} G_{\mathrm{M}_{2}} c_{\mathrm{M}_{2}}}
$$


Since the elements are directed along the principal stresses, it is required that

$$
\begin{aligned}
& x_{x y} G_{\mathrm{G}}=\alpha_{x y} \sqrt{{ }_{x} E_{\mathrm{G} y} E_{\mathrm{G}}}, \quad{ }_{y x} G_{\mathrm{G}}=\alpha_{y x} \sqrt{{ }_{y} E_{\mathrm{G} x} E_{\mathrm{G}}} \\
& { }_{y z} G_{\mathrm{G}}=\alpha_{y z} \sqrt{{ }_{y} E_{\mathrm{G} z} E_{\mathrm{G}}}, \quad{ }_{z y} G_{\mathrm{G}}=\alpha_{z y} \sqrt{{ }_{z} E_{\mathrm{G} y} E_{\mathrm{G}}} \\
& { }_{x z} G_{\mathrm{G}}=\alpha_{x z} \sqrt{{ }_{x} E_{\mathrm{G} z} E_{\mathrm{G}}}, \quad{ }_{z x} G_{\mathrm{G}}=\alpha_{z x} \sqrt{{ }_{z} E_{\mathrm{G} x} E_{\mathrm{G}}}
\end{aligned}
$$

where for the case of geomaterials in the elastic range one has [2]

$$
\begin{aligned}
\alpha_{i j} & =\frac{1}{2}\left(1+v_{i j}\right) \\
{ }_{i j} G_{\mathrm{G}} & =\frac{1}{2}\left(1+v_{i j}\right) \sqrt{{ }_{i} E_{\mathrm{G} j} E_{\mathrm{G}}} \\
v_{i j} & =\frac{2{ }_{i j} G_{\mathrm{G}}}{\sqrt{{ }_{i} E_{\mathrm{G} j} E_{\mathrm{G}}}}-1
\end{aligned}
$$

We therefore obtain for the different directions the corresponding Poisson's ratios

$$
\begin{aligned}
x y & v_{\mathrm{G}}=\frac{2_{x y} G_{\mathrm{G}}}{\sqrt{{ }_{x} E_{\mathrm{G} y} E_{\mathrm{G}}}}-1, \quad{ }_{y x} v_{\mathrm{G}}=\frac{2_{y x} G_{\mathrm{G}}}{\sqrt{{ }_{y} E_{\mathrm{G} x} E_{\mathrm{G}}}}-1 \\
x z & =\frac{2{ }_{\mathrm{G} z} G_{\mathrm{G}}}{\sqrt{{ }_{x} E_{\mathrm{G} z} E_{\mathrm{G}}}}-1, \quad{ }_{z x} v_{\mathrm{G}}=\frac{2_{z x} G_{\mathrm{G}}}{\sqrt{{ }_{z} E_{\mathrm{G} x} E_{\mathrm{G}}}}-1 \\
y z & v_{\mathrm{G}}=\frac{2_{y z} G_{\mathrm{G}}}{\sqrt{{ }_{y} E_{\mathrm{G} z} E_{\mathrm{G}}}}-1, \quad{ }_{z y} v_{\mathrm{G}}=\frac{2_{z y} G_{\mathrm{G}}}{\sqrt{{ }_{z} E_{\mathrm{G} y} E_{\mathrm{G}}}}-1
\end{aligned}
$$

where ${ }_{i j} v_{\mathrm{G}}$ represents the homogeneous Poisson's ratio in the $i j$ plane.

\subsection{Homogeneous plastic flow}

Beyond the elastic limit, which is defined by the modified Mohr-Coulomb criterion, the material exhibits plastic deformations. Here the stress state is represented by a point on the defined yield surface.

The masonry presents a marked anisotropic character (in the case of the proposed model the hypothesis of orthotropy has been assumed), while the yield criterion is defined for an isotropic space. For this reason, and in order to use a yield criterion defined in an isotropic space, the Theory of the Mapped Spaces is used to transform the anisotropic space into a fictitious isotropic space in which the evolution of the yield surface when the load increases can be followed.

As the associated plasticity hypothesis is assumed, the function $f(\tau)$ describing the MohrCoulomb yield surface and the plastic potential $g(\tau)$ coincide in the fictitious isotropic space. 
The plastic yield function is expressed in the following form:

$$
f(\tau)-c_{\mathrm{G}}\left(\kappa^{\mathrm{p}}\right)>0
$$

where $f(\tau)$ is the yield function of the modified Mohr-Coulomb law, $c_{\mathrm{G}}\left(\kappa^{\mathrm{p}}\right)$ is the cohesion of the homogeneous material, function of the damage parameter $\kappa^{\mathfrak{p}}[9]$, and $\tau$ the stress tensor in the fictitious isotropic space [6].

The value of the homogenized cohesion is obtained from expression (13a) developed for mode 3 of deformation of the constitutive model. It can also be obtained from equation (9) developed for mode 2

$$
c_{\mathrm{G}}\left(\kappa^{\mathrm{p}}\right)=c_{\mathrm{L}}\left(\kappa^{\mathrm{p}}\right) \frac{l_{\mathrm{L}}}{l_{\mathrm{G}}}+c_{\mathrm{M}_{1}}\left(\kappa^{\mathrm{p}}\right) \frac{l_{\mathrm{M}_{1}}}{l_{\mathrm{G}}}
$$

The value of the damage parameter $\kappa^{\mathrm{p}}$ is assumed to be a direct sum of the plastic damage parameters of each one of the components [9]

$$
\kappa^{\mathrm{p}}=\kappa_{\mathrm{L}}^{\mathrm{P}}+\kappa_{\mathrm{M}_{1}}^{\mathrm{P}}+\kappa_{\mathrm{M}_{2}}^{\mathrm{P}}
$$

In the case of homogenization techniques, unlike micromodels, the cracks are not assumed to be localized in any particular place, in the joints or in the bricks, since the composite material is treated as homogeneous.

When equation (30) is obeyed, the total homogeneous strain can be expressed as the sum of elastic and a plastic component:

$$
{ }_{i} \varepsilon_{\mathrm{G}}={ }_{i} \varepsilon_{\mathrm{G}}^{\mathrm{e}}+{ }_{i} \varepsilon_{\mathrm{G}}^{\mathrm{p}}
$$

The different components of the plastic deformation are obtained from the development presented in this section.

From expression (8) the global plastic flow is obtained

$$
{ }_{x} \varepsilon_{\mathrm{G}}^{\mathrm{p}}=A_{x}^{\mathrm{p}}\left({ }_{x} \varepsilon_{\mathrm{M}_{2}}^{\mathrm{p}} l_{\mathrm{M}_{2}}-{ }_{x} \varepsilon_{\mathrm{L}}^{\mathrm{p}} l_{\mathrm{L}}-{ }_{x} \varepsilon_{\mathbf{M}_{1}}^{\mathrm{p}} l_{\mathrm{M}_{1}}\right)+\left({ }_{x} \varepsilon_{\mathrm{L}}^{\mathrm{p}} \frac{l_{\mathrm{L}}}{l_{\mathrm{G}}}+{ }_{x} \varepsilon_{\mathrm{M}_{1}}^{\mathrm{p}} \frac{l_{\mathrm{M}_{1}}}{l_{\mathrm{G}}}\right)
$$

Due to the fact that we take a homogenized surface for the homogenized material we can write the previous expression depending on Mohr-Coulomb plastic strain $\left.{ }_{x} \varepsilon_{\mathrm{G}}^{\mathrm{p}}\right|_{\text {Mohr }}$

$$
\begin{gathered}
{ }_{x} \varepsilon_{\mathrm{G}}^{\mathrm{p}}=\left.A_{x}^{\mathrm{p}}\left(l_{\mathrm{M}_{2}}-l_{\mathrm{L}}-l_{\mathrm{M}_{1}}\right)_{x} \varepsilon_{\mathrm{G}}^{\mathrm{p}}\right|_{\mathrm{Mohr}}+\left.\left(\frac{l_{\mathrm{L}}}{l_{\mathrm{G}}}+\frac{l_{\mathrm{M}_{1}}}{l_{\mathrm{G}}}\right){ }_{x} \varepsilon_{\mathrm{G}}^{\mathrm{p}}\right|_{\mathrm{Mohr}} \\
{ }_{x} \varepsilon_{\mathrm{G}}^{\mathrm{p}}=\left.\left[A_{x}^{\mathrm{p}} l_{\mathrm{M}_{2}}+\left(\frac{1}{l_{\mathrm{G}}}-A_{x}^{\mathrm{p}}\right)\left(l_{\mathrm{L}}+l_{\mathrm{M}_{1}}\right)\right]{ }_{x} \varepsilon_{\mathrm{G}}^{\mathrm{p}}\right|_{\mathrm{Mohr}}
\end{gathered}
$$

where

$$
A_{x}^{\mathrm{p}}=\frac{{ }_{x} E_{\mathrm{L} x} E_{\mathrm{M}_{1} x} E_{\mathrm{M}_{2}} h_{\mathrm{M}_{2}}}{{ }_{x} E_{\mathrm{M}_{1} x} E_{\mathrm{M}_{2}} h_{\mathrm{M}_{2}} l_{\mathrm{L}}+{ }_{x} E_{\mathrm{L} x} E_{\mathrm{M}_{2}} h_{\mathrm{M}_{2}} l_{\mathrm{M}_{2}}+{ }_{x} E_{\mathrm{L} x} E_{\mathrm{M}_{1}} h_{\mathrm{M}_{2}} l_{\mathrm{M}_{1}}}\left(\frac{l_{\mathrm{L}}}{{ }_{x} E_{\mathrm{L}} l_{\mathrm{G}}}+\frac{l_{\mathrm{M}_{1}}}{{ }_{x} E_{\mathrm{M}_{1}} l_{\mathrm{G}}}\right)
$$


From equation (12) developed for mode 2:

$$
{ }_{y} \varepsilon_{\mathrm{G}}^{\mathrm{p}}=A_{y}^{\mathrm{p}}\left(-{ }_{y} \varepsilon_{\mathrm{L}}^{\mathrm{p}} h_{\mathrm{L}}+{ }_{y} \varepsilon_{\mathrm{M}_{1}}^{\mathrm{p}} h_{\mathrm{M}_{1}}\right)+\left({ }_{y} \varepsilon_{\mathrm{L}}^{\mathrm{p}} \frac{h_{\mathrm{L}}}{h_{\mathrm{G}}}+{ }_{y} \varepsilon_{\mathrm{M}_{1}}^{\mathrm{p}} \frac{h_{\mathrm{M}_{2}}}{h_{\mathrm{G}}}\right)
$$

Given the same yield surface for all the deformations as the previous case

$$
\begin{aligned}
& { }_{y} \varepsilon_{\mathrm{G}}^{\mathrm{p}}=\left.A_{y}^{\mathrm{p}}\left(-h_{\mathrm{L}}+h_{\mathrm{M}_{1}}\right)_{y} \varepsilon_{\mathrm{G}}^{\mathrm{p}}\right|_{\mathrm{Mohr}}+\left.\left(\frac{h_{\mathrm{L}}}{h_{\mathrm{G}}}+\frac{h_{\mathrm{M}_{2}}}{h_{\mathrm{G}}}\right){ }_{y} \varepsilon_{\mathrm{G}}^{\mathrm{p}}\right|_{\mathrm{Mohr}} \\
& { }_{y} \varepsilon_{\mathrm{G}}^{\mathrm{p}}=\left.\left[A_{y}^{\mathrm{p}} h_{\mathrm{M}_{1}}+\left(\frac{1}{h_{\mathrm{G}}}-A_{y}^{\mathrm{p}}\right) h_{\mathrm{L}}+\frac{h_{\mathrm{M}_{2}}}{h_{\mathrm{G}}}\right]{ }_{y} \varepsilon_{\mathrm{G}}^{\mathrm{p}}\right|_{\mathrm{Mohr}}
\end{aligned}
$$

where

$$
A_{y}^{\mathrm{p}}=\frac{{ }_{y} E_{\mathrm{L} y} E_{\mathrm{M}_{1}} l_{\mathrm{M}_{1}}}{{ }_{y} E_{\mathrm{M}_{1}} l_{\mathrm{M}_{1}} h_{\mathrm{L}}+{ }_{y} E_{\mathrm{L}} l_{\mathrm{L}} h_{\mathrm{M}_{1}}} \frac{h_{\mathrm{L}}}{E_{\mathrm{L}} h_{\mathrm{G}}}
$$

From equation (17) developed for mode 3

$$
{ }_{x y} \gamma_{\mathrm{G}}^{\mathrm{p}}=A_{\gamma}^{\mathrm{p}}\left({ }_{x y} \gamma_{\mathrm{L}}^{\mathrm{p}}-{ }_{x y} \gamma_{\mathrm{M}_{1}}^{\mathrm{p}}\right)+{ }_{x y} \gamma_{\mathrm{L}}^{\mathrm{p}} \frac{h_{\mathrm{L}}}{h_{\mathrm{G}}}+{ }_{x y} \gamma_{\mathrm{M}_{2}}^{\mathrm{p}} \frac{h_{\mathrm{M}_{2}}}{h_{\mathrm{G}}}
$$

Due to the fact that we take a homogenized surface for the homogenized material we can write the previous expression as

$$
\begin{gathered}
x y \gamma_{\mathrm{G}}^{\mathrm{p}}=A_{\gamma}^{\mathrm{p}}\left(\left.{ }_{x y} \gamma_{\mathrm{G}}^{\mathrm{p}}\right|_{\mathrm{Mohr}}-\left.{ }_{x y} \gamma_{\mathrm{G}}^{\mathrm{p}}\right|_{\mathrm{Mohr}}\right)+\left.{ }_{x y} \gamma_{\mathrm{G}}^{\mathrm{p}}\right|_{\mathrm{Mohr}} \frac{h_{\mathrm{L}}}{h_{\mathrm{G}}}+\left.{ }_{x y} \gamma_{\mathrm{G}}^{\mathrm{p}}\right|_{\mathrm{Mohr}} \frac{h_{\mathrm{M}_{2}}}{h_{\mathrm{G}}} \\
x y \gamma_{\mathrm{G}}^{\mathrm{p}}=\left.\left(\frac{h_{\mathrm{L}}+h_{\mathrm{M}_{2}}}{h_{\mathrm{G}}}\right){ }_{x y} \gamma_{\mathrm{G}}^{\mathrm{p}}\right|_{\mathrm{Mohr}}
\end{gathered}
$$

where

$$
A_{\gamma}^{\mathrm{p}}=G_{\mathrm{M}_{1}} \frac{l_{\mathrm{M}_{1}}}{l_{\mathrm{G}}}\left(\frac{G_{\mathrm{L}} l_{\mathrm{G}}}{G_{\mathrm{L}} l_{\mathrm{L}}+G_{\mathrm{M}_{1}} l_{\mathrm{M}_{1}}}\right) \frac{h_{\mathrm{L}}}{G_{\mathrm{L}} h_{\mathrm{G}}}
$$

From expression (19) we obtain directly

$$
{ }_{z} \varepsilon_{\mathrm{G}}^{\mathrm{p}}=\frac{\left.\left({ }_{x z} v_{\mathrm{G}}+{ }_{x y} v_{\mathrm{G} y z} v_{\mathrm{G}}\right)_{x} \varepsilon_{\mathrm{G}}^{\mathrm{p}}\right|_{\mathrm{Mohr}}+\left.\left(_{y z} v_{\mathrm{G}}+{ }_{x z} v_{\mathrm{G} y x} v_{\mathrm{G}}\right)_{y} \varepsilon_{\mathrm{G}}^{\mathrm{p}}\right|_{\mathrm{Mohr}}}{\left(-1+{ }_{x y} v_{\mathrm{G} y x} v_{\mathrm{G}}\right)}
$$

From expressions (33)-(36) we obtain the vector of plastic deformations in masonry model case as a function of the vector calculated according to Mohr-Coulomb theory

$$
\dot{\varepsilon}_{\mathrm{G}}^{\mathrm{p}}=\left.\mathbf{M}^{\mathrm{p}} \dot{\varepsilon}^{\mathrm{p}}\right|_{\mathrm{Mohr}}
$$


where $\left.\dot{\varepsilon}^{\mathrm{p}}\right|_{\text {Mohr }}$ is the classic Mohr-Coulomb plastic flow and $\dot{\varepsilon}_{\mathrm{G}}^{\mathrm{p}}$ is the modified masonry plastic flow. The transformation plastic flow tensor is expressed as

$$
M^{\mathrm{p}}=\left[\begin{array}{cccc}
{\left[A_{x}^{\mathrm{p}} l_{M_{2}}+\left(\frac{1}{l_{\mathrm{G}}}-A_{x}^{\mathrm{p}}\right)\left(l_{\mathrm{L}}+l_{\mathrm{M}_{1}}\right)\right]} & 0 & 0 \\
0 & {\left[A_{y}^{\mathrm{p}} h_{\mathrm{M}_{1}}+\left(\frac{1}{h_{\mathrm{G}}}-A_{y}^{\mathrm{p}}\right) h_{\mathrm{L}}+\frac{h_{\mathrm{M}_{2}}}{h_{\mathrm{G}}}\right]} & 0 & 0 \\
0 & 0 & \frac{h_{\mathrm{L}}+h_{\mathrm{M}_{2}}}{h_{\mathrm{G}}} & 0 \\
\frac{x{ }_{z z} v+{ }_{x y} v_{y z} v}{-1+{ }_{x y} v_{y x} v} & \frac{{ }_{y z} v+{ }_{x z} v_{y z} v}{-1+{ }_{x y} v_{y x} v} & 0
\end{array}\right]
$$

While the problem is being treated with the Mohr-Coulomb yield criterion and plastic potential, nonetheless, the plastic flow is non-associated by virtue of orientation change effected by the tensor $\mathbf{M}^{\mathrm{p}}$ (see (37)).

\section{VALIDATION EXAMPLES}

\subsection{Calibration example}

In order to calibrate the model the experimental results of Page [7] have been used. This test is one of those most commonly used in the calibration of numerical models of masonry. Lourenço [8] also used this test for calibrating his model, which will also be compared with the results of the model proposed here.

The dimensions of the panel were $75.7 \times 45.7 \times 5.4 \mathrm{~cm}^{3}$, using bricks of $12.2 \times 3.7 \times 5.4 \mathrm{~cm}^{3}$ with joints $0.5 \mathrm{~cm}$ thick. The mechanical characteristics of the materials used are summarized in Table I. The test gives values of stresses and vertical deformations in a line of gauges arranged at $18.65 \mathrm{~cm}$ from the baseline. The load $(P)$ is applied with a piston and transmitted through a steel beam over a length of $38.1 \mathrm{~cm}$ (see Figure 4).

Since no measurements of energies of fracture and plastic deformation in compression were made, fracture energies of $G_{\mathrm{f}}^{\mathrm{M}}=8.32$ and $G_{\mathrm{f}}^{\mathrm{L}}=207.36 \mathrm{~kg} / \mathrm{cm}$ were assumed for the mortar

Table I. Mechanical parameters of the masonry

\begin{tabular}{lc}
\hline Property & Value \\
\hline Elastic modulus for loading parallel to the base line $E_{x}\left(\right.$ in $\left.\mathrm{kg} / \mathrm{cm}^{2}\right)$ & 59200 \\
Elastic modulus for loading perpendicular to the base line $E_{y}\left(\mathrm{in} \mathrm{kg} / \mathrm{cm}^{2}\right)$ & 75500 \\
$E_{y} / E_{x}$ & $1 \cdot 35$ \\
In-plane Poisson ratio & $0 \cdot 167$ \\
Compressive strength of the brick (in $\left.\mathrm{kg} / \mathrm{cm}^{2}\right)$ & $362 \cdot 5$ \\
Compressive strength of the mortar $\left(\mathrm{in} \mathrm{kg} / \mathrm{cm}^{2}\right)$ & 32 \\
Internal angle of friction & $30^{\circ}$ \\
Elastic modulus for the mortar $\left(\mathrm{in} \mathrm{kg} / \mathrm{cm}^{2}\right)$ & 8041 \\
\hline
\end{tabular}




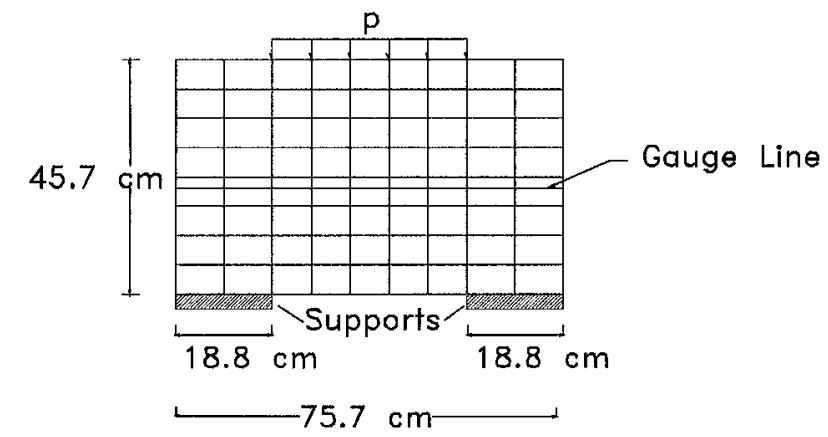

Figure 4. Configuration of the Page test

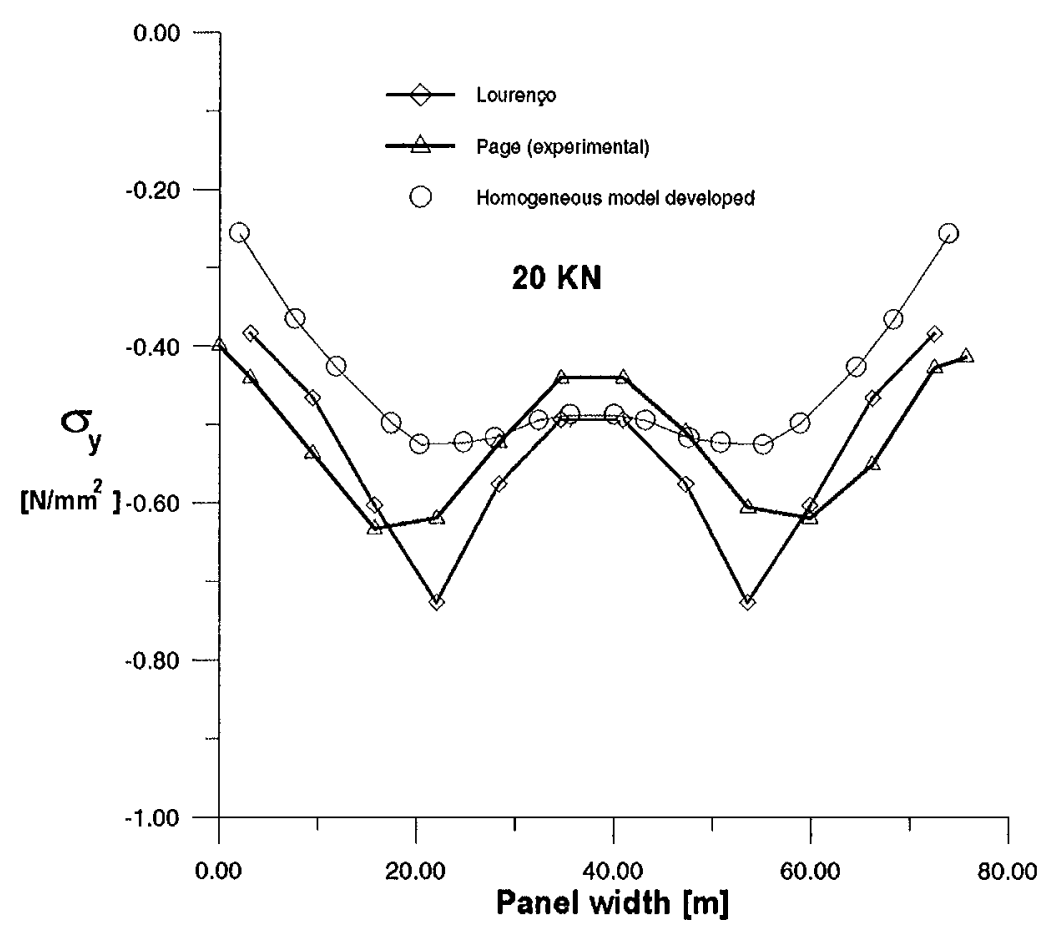

Figure 5. Stress-strain curves for $20 \mathrm{kN}$

and brick, respectively. For the energy of plastic deformation in compression, values of $G_{\mathrm{c}}^{\mathrm{M}}=384 \mathrm{~kg} / \mathrm{cm}$ for the mortar and $G_{\mathrm{c}}^{\mathrm{L}}=592 \mathrm{~kg} / \mathrm{cm}$ for the brick were assumed. Large values were chosen for these parameters in order to obtain better convergence of the constitutive equations at high stress levels. The fundamental objective is not the simulation of the post-peak response, and therefore, the adaptation of these values is considered to be acceptable.

The test was performed for the loads of 20,40 and $60 \mathrm{kN}$, and the results obtained are given in Figures 5-7. The gauges coincide with the positions of the top Gauss points of the elements in the intermediate band and therefore the results have been used for these Gauss points. 


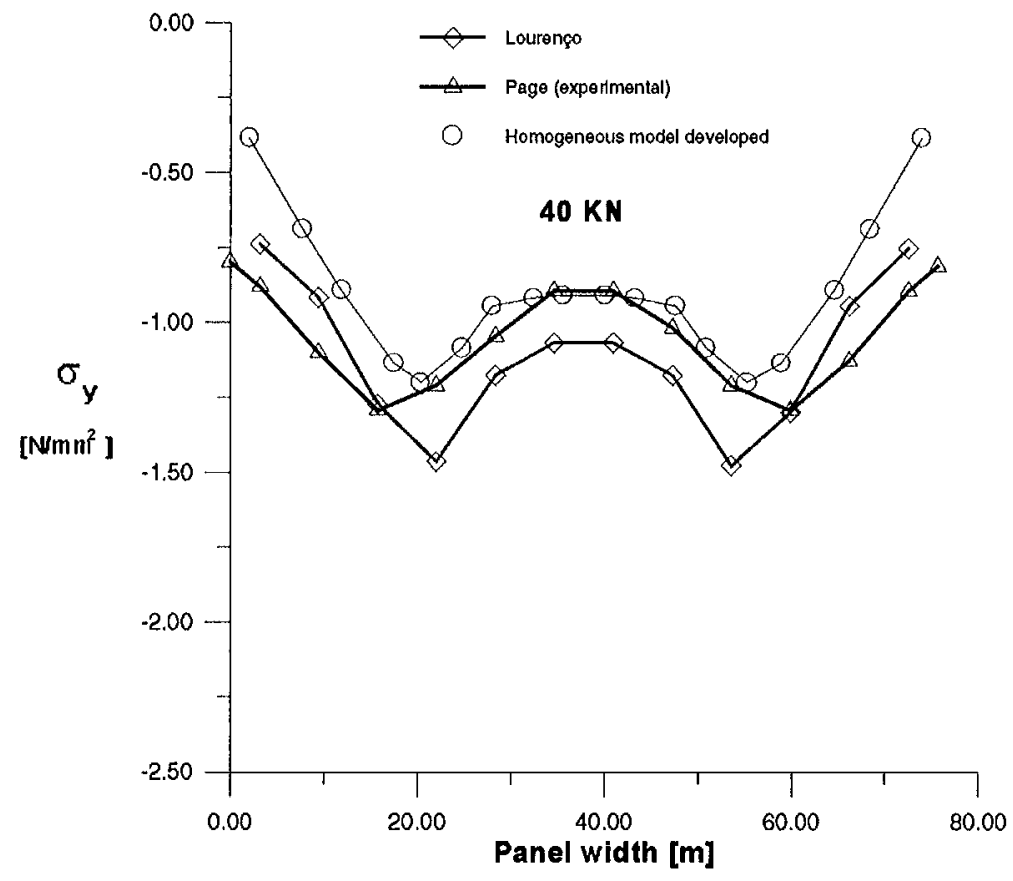

Figure 6. Stress-strain curves for $40 \mathrm{kN}$

The generated mesh had 72 four-node elements, each with 4 Gauss points. In order to study the response of the model with a small number of elements, more elements were not used in the analysis since fine meshes would not demonstrate the advantages compared with simplified micromodels where the joints and bricks are discretized by separate elements. The usefulness of this type of homogenization is in the ability to save on computational time and simplify the mesh generation process.

In the following, a comparison is made between the stress states of the three tests along the line of the gauges $([7,8]$ the proposed model). A step loading process is used and the characteristic values are determined.

It can be seen in the plots that the modelling is good with the exception of the extremes which could have been distorted by (an experimental cause) local effects in the band of measurements or (a numerical cause) due to the fact that the Gauss point does not coincide exactly with the position of gauge since this is not specified. Also, the lack of adequate discretization could cause this poor approximation. Furthermore, a methodology for the masonry behaviour is here presented, but not a specific model for each material compounding. Due to this fact a better approximation can be used for the mortar and brick behaviour.

Another conclusion is that the behaviour is better at high stress levels beyond the elastic limit since the $\mathrm{P}-\delta$ diagram, from which the energies of fracture and plastic deformation in compression are obtained, is taken to be linear while the real law is exponentially decreasing. 


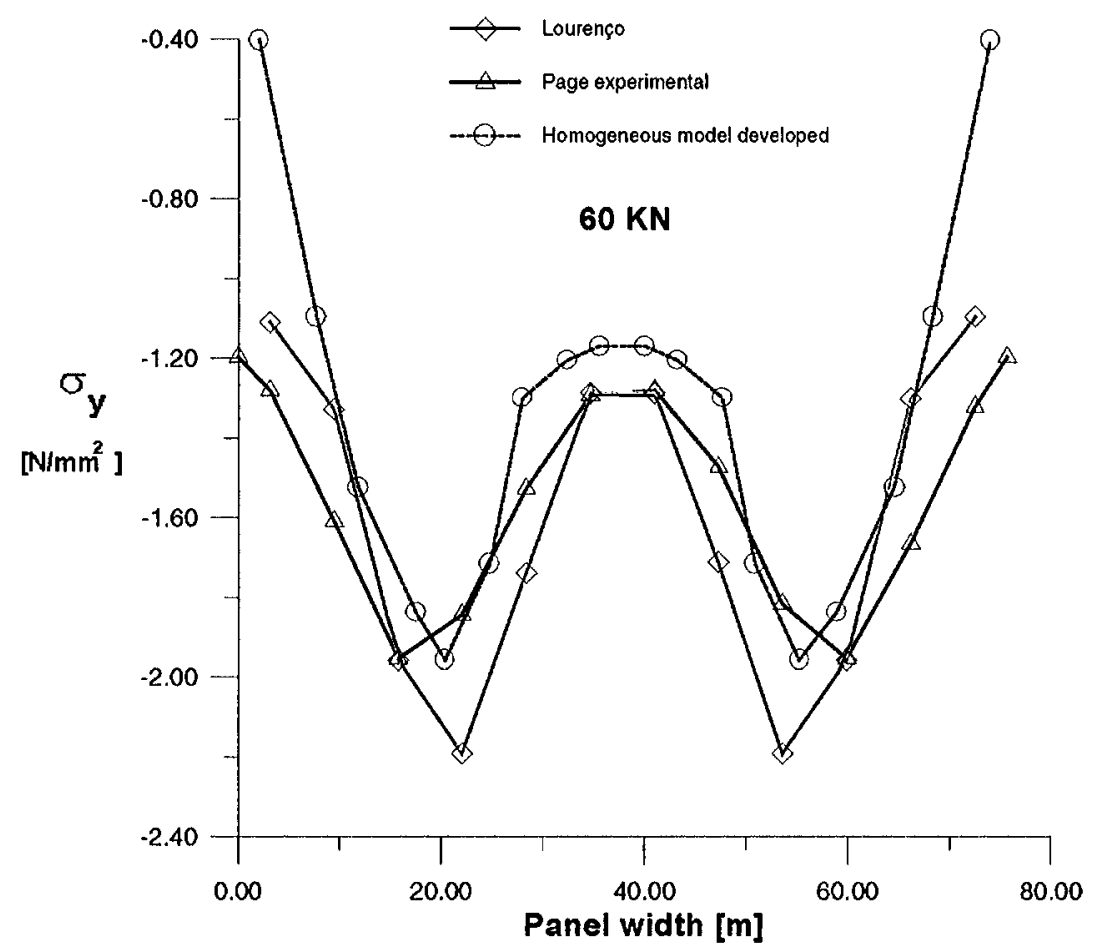

Figure 7. Stress-strain curve for $60 \mathrm{kN}$

\subsection{Practical example}

In order to see a practical example, an edification panel built with the same material of the previous example and loaded with gravitational load plus an increased external vertical uniform load applied at the top and the middle height is presented as shown in Plate 1. The finite element mesh was made with 560 elements with four nodes each one.

\section{CONCLUSIONS}

Masonry is a composite material made up of components, such as mortar and bricks, with different mechanical characteristics. This heterogeneity in the composition along with the arrangement of the elements (bricks and joints) lead to a combination that is strongly anisotropic. Variations on the joints or the loading orientation lead to different behaviours.

The homogenized model permits the simplified treatment of masonry. The treatment of the geometry through structured meshes with quadrilateral elements reflects better the real arrangement of the joints and bricks in the masonry. This type of mesh leads to more simple mesh generation. 
The homogenization technique considerably reduces the time for the processes of mesh generation and computation. The number of elements needed is much smaller than in macromodels.

The homogenization technique is optimal for large structures where the use of individual elements for each component is not practical for mesh generation.

The micromodels are advantageous when compared with macromodels, being efficient for studies of local details.

The homogenized model developed here is not capable of identifying the fracture mechanisms but can identify the damage zone, which can be associated with the type of cracking through the analysis of the stress state of these elements.

The anisotropy of the masonry can be adequately handled through the use of the Space Transformation Theory.

The model permits the use of joints orientated in different directions with respect to the reference system axes.

\section{REFERENCES}

1. Anthoine A. Derivation of the in-plane elastic characteristics of masonry through homogeneization theory. Journal of Solids Structures 1995; 32(2):137-163.

2. Luccioni B. Formulación de un Modelo Constitutivo para Materiales Ortótropos. Tesis Doctoral. Universidad Nacional de Tucumán, Argentina, 1993.

3. Pietruszcak S, Niu X. A mathematical description of macroscopic behaviour of brick masonry. Journal of Solids Structures 1992; (29):531-546.

4. Neamtu L, Oller S, Oñate E. A generalized mixing theory elasto-damage-plastic model for finite element analysis of composites. In Complas V, Owen R, Oñate E, Hinton E (eds). Barcelona, March, 1997; 1214-1219.

5. López J. Formulación de un Modelo Constitutivo Homogeneizado para Mampostería. Tesina de Especialidad, Universidad Politécnica de Cataluña, Barcelona, 1997.

6. Oller S, Botello S, Miquel Canet J, Oñate E. An anisotropic elasto-plastic model based on an isotropic formulation. International Journal for Computer -Engineering Computation 1995; 12(3):245-262.

7. Page AW. Finite element model for masonry. Journal of the Structural Division, ASCE, 1978; 104(ST8): Proc. Paper 13957, 1267-1285.

8. Lourenço PB. Computational strategies for masonry structures. Doctoral thesis, Delft University of Technology, Delft University Press, 1996.

9. Lubliner J, Oliver J, Oller S, Oñate E. A plastic-damage model for concrete. International Journal of Solids and Structures $1989 ; \mathbf{2 5}(3): 299-326$.

10. Oller S, Oñate E, Miquel Canet J, Botello S. A plastic damage constitutive model for composite materials. International Journal of Solids and Structures 1996; 33(17):2501-2518.

11. Oller S, Oñate E. A hygro-thermo-mechanical constitutive model for multiphase composite materials. International Journal of Solids and Structures 1996; 33(20-22):3179-3186.

12. Oñate E, Hanganu A, Barbat A, Oller S, Vitaliani R, Saetta A, Scotta R. Structural analysis and durability assesment of historical constructions using a finite element damage model. Publication CIMNE No. 73. Barcelona, 1996.

13. Lenczner D. Creep in brickwork with and without damp proof courses. Proceedings of the British Ceramic Society. No. 21, 1973; 39-49. 